\title{
NISTIR 5903
}

\section{Mechanical Properties of Aluminum Nitride Substrates}

J.S. Wallace

E.R. Fuller, Jr.

S.W. Freiman

Ceramics Division

U.S. DEPARTMENT OF COMMERCE Technology Administration National Institute of Standards and Technology

Materials Science and Engineering Laborator y (MSEL) Gaithersburg, MD 20899-0001

QC

100

.U56

NO.5903 



\section{J.S. Wallace E.R. Fuller, Jr. S.W. Freiman \\ Ceramics Division}

U.S. DEPARTMENT OF COMMERCE Technology Administration National Institute of Standards and Technology Materials Science and Engineering Laboratory (MSEL) Gaithersburg, MD 20899-0001

December 1996

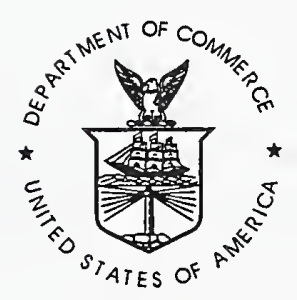

U.S. DEPARTMENT OF COMMERCE Michael Kantor, Secretary

TECHNOLOGY ADMINISTRATION Mary L. Good, Under Secretary for Technology

NATIONAL INSTITUTE OF STANDARDS

AND TECHNOLOGY

Arati Prabhakar, Director 


\section{INTRODUCTION}

Basic research is being conducted to characterize the mechanical reliability of aluminum nitride (AlN) substrates for use in advanced heat management applications. Because of its high thermal conductivity, AlN has performance advantages in myriad high-density, high-power applications, e.g., multichip modules, discrete RF device packaging, and high-power switching devices. However, thermal gradients, joining stresses, and packaging forces can result in large stresses in the AIN substrates. Accordingly, mechanical properties, particularly strength distributions and long-term strength degradation, become important aspects of overall reliability of these devices. Development of high reliability substrate materials thus requires characterization of mechanical properties, particularly when new powders and low firing compositions are developed.

This research is a four-way collaboration between Dow Chemical Co. in Midland, Michigan, who provides AlN powder to Toshiba's Research and Development Center in Japan to make test specimens. NIST develops and conducts tests for characterizing the mechanical behavior of AlN substrates, and Japan's National Industrial Research Laboratory of Nagoya (NIRIN) is responsible for processing studies and microstructural characterization. The research is pre-competitive to avoid intellectual property rights issues. This report describes the research conducted at NIST.

\section{TESTING CONFIGURATION DESIGN}

Development of high-reliability substrate materials requires the characterization of mechanical properties for developmental materials which are fabricated with new powders and compositions. Unfortunately, the usual techniques for evaluating strength, three- and four-point bending of bar samples, are incompatible with the geometry of the thin, tape-cast plates used as substrates; standardized strength testing techniques from $\mathrm{ASTM}^{1}$, European Standard ${ }^{2}$ and JIS $^{3}$ require specimen thicknesses of $3-4 \mathrm{~mm}$, far greater than the $0.5-1 \mathrm{~mm}$ found in tape-cast substrates which typically have 2 to 3 tape layers. Although lamination of 15 to 20 ceramic tapes prior to sintering could produce the required testing thicknesses, this would still preclude the characterization of production materials. Furthermore, questions arise as to whether thick laminated materials are representative of thinner production substrate materials.

Requirements of the current bend-strength standards present another problem: 
dimensional tolerances and flatness mandate that samples be machined, limiting the ability to characterize the strength of as-fired and finished surfaces. For these reasons, it is desirable to utilize a alternate technique for characterizing thin electronic substrate materials. The geometry of the substrates virtually dictates that a biaxial flexure condition be applied for testing. The biaxial flexure testing techniques which have been utilized are: piston on three balls, ${ }^{4,5,6}$ ball on three balls, ${ }^{6}$ ball on ring, ${ }^{7}$ uniform hydraulic pressure ${ }^{8}$ and coaxial ring. ${ }^{9}$ The strong and weak points of each of these techniques will be discussed in turn.

\section{Piston-on-Three-Balls Configuration}

The test requirements for piston on three balls have been formalized in ASTM standard F $394-78 .{ }^{5}$ One sample face is supported on three balls and the load is applied to the opposite surface by a flat, unarticulated piston. The stress state on the surface opposite the piston is biaxial tension on the surface with constant stress directly opposite the piston. Two potential sources of error, load point friction at the piston and mirroring of contact stress opposite the piston, have been addressed in the standard by the use of a compliant $0.05 \mathrm{~mm}$ thick polyethylene film between the piston and sample. The polyethylene film acts as a compliant layer, lowering the contact stresses and friction. However, two major sources of error still exist for this test technique. First, since the upper loading piston is not articulated, any warpage of the specimen, particularly for as-fired surfaces, or misalignment of the machine will result in a non-uniform stress state. Also, the relatively large span of the load points on the tensile surface $(25.4 \mathrm{~mm}$ load circle diameter) requires the use of relatively large specimen thickness in order to avoid excess deflection and the accompanying nonlinear elastic "membrane" stresses. These large spans, as compared to the sample size, also result in significant stresses along the outside edges of the sample, resulting in increased probability of sample edge failure which would bias the test results.

\section{Ball-on-Three-Balls Configuration}

The testing procedures for the ball on three balls, ${ }^{6}$ in which the specimen surface is supported on three balls and the load is applied on the opposite surface through a single central ball, have not been formalized as an international standard. In general, however, the technique has different advantages and disadvantages to the ASTM standard. Although problems associated with sample warpage are completely avoided, mirroring of contact stresses onto the tensile surface is probably more severe than for the piston on three balls. Since the tensile bending stress and tensile stress opposite the contact are additive, a large nonuniform 
tensile results. A further disadvantage is the very small volume of material under maximum stress, similar to the condition existing in three point bending of bars.

\section{Ball-on-Ring Configuration}

The ball on ring configuration ${ }^{7}$ replaces the three lower supporting balls of the ball on three balls with a ring. As a result, in addition to the problems of the ball on three balls configuration, contact friction and specimen warpage become potential problems.

\section{Uniform-Hydraulic-Pressure Configuration}

Another test configuration which has been used employs a hydraulic bladder to apply a uniform load to the face of the sample. ${ }^{8}$ The use of the flexible hydraulic bladder completely avoids problems of friction and contact stresses but results in a nonuniform stress state, much like three point bending. As a result, only in a very small volume of the sample is found under maximum stress. Also, since the support of the tensile surface is rigid, potential problems with specimen nonuniformities and warpage still exist.

\section{Coaxial-Ring or Ring-on-Ring Configuration}

The coaxial ring 9 or ring-on-ring configuration has much in common with the previous techniques in that a biaxial stress state is formed. Here, however, a relatively large volume of the sample can be under test. As with the other techniques, potential sources of error are friction at the loading points, mirroring of contact stresses from the loading ring onto the tensile surface, excess specimen deflections resulting in "membrane" stresses and high stress at the sample edges resulting in edge failures. Design of the fixture can minimize the potential sources of error; each design condition will be discussed in turn.

Friction: Friction at the loading points is a potential source of error as it results in constraint of the sample as the sample deflects elastically under load. In four-point bend testing, friction can be avoided through the use of rolling loading points. In a coaxial ring fixture, friction can be minimized by the use of rolling contact elements such as rolling balls or "soft" contacting elements, such as springs or low elastic modulus rings. Rolling balls offer the lowest potential friction solution. Unfortunately, since the balls must roll both towards and away from the center of the sample depending on the sample deflection, ${ }^{10}$ precise location of the loading balls at the start of the test, which is critical for determining the loading 
geometry, is extremely difficult. Soft contacting elements, such as metal springs ${ }^{6}$ and polymers with low modulii, ${ }^{11}$ have been successfully employed. For the ease of fabrication of the fixture and loading elements, the latter solution is preferred. Acetyl polymer, which has a low coefficient of friction, low elastic modulus (3.6 GPa) and high compressive strength $(124 \mathrm{MPa}){ }^{12}$ is one such material.

Contact Stresses: As noted previously, compressive contact stresses that exist at the loading elements are mirrored as tensile stress onto the opposite surface. ${ }^{13}$ If the stress state on the opposite surface is tensile, superposition results in an increased stress which could result in failure of the sample at a stress level lower than the nominal calculated stress. Two techniques exist for minimizing contact stresses: (1) increasing the contact area of the loading ring; and (2) reducing the elastic modulus of the loading ring. For a loading ring with a square shoulder and a given diameter, the contact stress can be decreased for a given load by increasing the width of the ring, thus increasing the area of the ring in contact with the sample. As the width increases, however, elastic solutions for the stress state in the sample, which assume uniform contact stress across the width of the ring

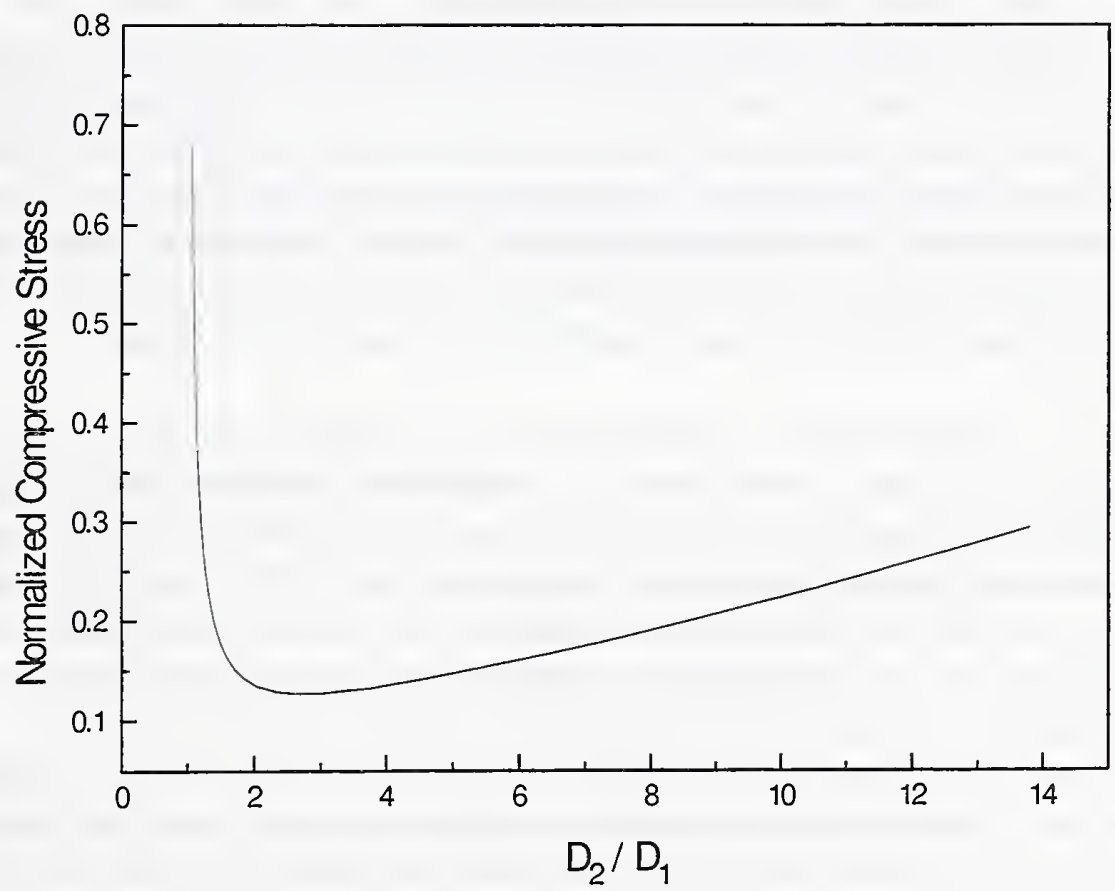

Figure 1. Normalized compressive stress for a range of ring diameter ratios. 
section, become less accurate. This effectively limits the ring width to a small fraction of the ring diameter. A second method for minimizing the contact stress, for a given ring width, is by varying ratio of the outer loading ring diameter, $\mathrm{D}_{2}$, to the inner loading ring diameter, $D_{1}$. As the inner loading ring increases in diameter, the area in contact with the sample also increases. However, since the loading moment arm, which results in bending of the specimen, decreases as the distance between the inner and outer rings decreases, the load needed to attain a given stress level in the sample increases. A plot of the contact compressive stress normalized by the maximum stress in the sample for a range of ring radii ratios (Fig. 1) shows that there is a relatively low normalized compressive stress for ratios of ring radii between 2 and 8 . This range of radius ratios is one constraint for the design of a coaxial ring fixture. In order to further minimize contact stresses, low modulus polymer loading rings assures that any geometrical mismatch between the ring and specimen, such as specimen warpage, does not lead to high localized contact stresses. Although the low modulus ring material can also accommodate some small degree of testing machine and fixture misalignment, a fully articulated fixture with polymer loading rings further reduces these potential sources of error.

Membrane Stresses: When the deflection of the sample under test becomes large with respect to the sample thickness, elastic solutions for the stress state in the sample are no longer valid. ${ }^{14}$ Typically, maximum deflections on the order of one half the specimen thickness are acceptable. For a given stress in the sample, the deflection depends on the geometry of the test fixture. When the deflection of the sample is normalized by the thickness and plotted with respect to the ratio of the diameters of the outer and inner loading rings for a square specimen having the appropriate elastic constants for $\mathrm{AlN}\left(\mathrm{E}=308 \mathrm{GPa}^{15}\right.$ and $\left.v=0.23\right)$, Fig. 2 illustrates that excess deflection is unimportant for the range of radii ratios investigated.

Edge Stresses: It is difficult to avoid damage along the edges of samples during normal machining and handling. Although the edges of the plates in coaxial ring testing are outside of the load points, significant stress may still be applied to the edges as a result of the "cupping" of the sample. Severe damage, in combination with large applied stress at the edges, can result in edge failures which bias the strength data. In three- and four-point bend testing of bars, edge failures are avoided by rounding or chamfering the edges of the bars. ' In coaxial ring testing, sufficient amount of sample overhanging the outer fixture loading ring decreases the level of stress to the point that edge failure becomes unlikely even for the most severe defects. Literature references ${ }^{16}$ show that the value of stress at the edge is 


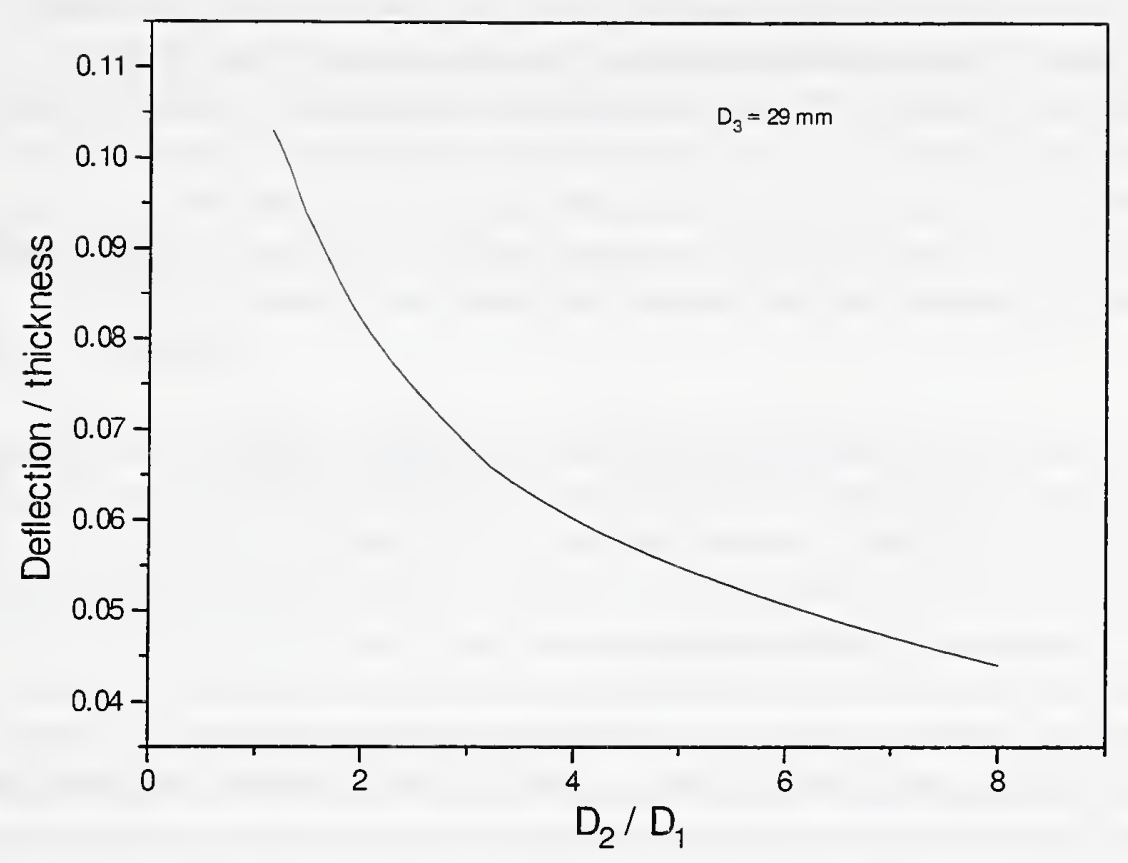

Figure 2. Deflection of a $29 \mathrm{~mm}$ edge length AlN sample for a range of loading ring diameter ratios.

approximately $10 \%$ of the maximum stress in the sample when $\left(D_{3}-D_{2}\right)>12 t$, where $\mathrm{D}_{3}$ is the sample diameter for round samples or 1.2 times the edge length, $\mathrm{L}$, for square samples. ${ }^{9}$ It is believed that this is a safe, practical value.

Final Coaxial-Ring Configuration: These design considerations result in the following fixture design constraints:
- $\quad 2<\mathrm{D}_{2} / \mathrm{D}_{1}<8$, to minimize loading ring contact stress
- $\quad \mathrm{D}_{2} / \mathrm{D}_{1}>1.5$, to minimize nonlinear elastic effects
- $\quad\left(D_{3}-D_{2}\right)>12 t$, to minimize edge failures.

Rearranging and substituting values for present smallest expected specimen size, square $20 \times 20 \times 0.7 \mathrm{~mm}$ AlN specimens, the last constraint gives:

$$
D_{2}<D_{3}-12 t=1.2(20 \mathrm{~mm})-12(0.7 \mathrm{~mm})=15.6 \mathrm{~mm}
$$


To maximize the volume of material under test and to minimize the normalized compressive contact stress at the loading ring, a ratio of outer-ring diameter to inner-ring diameter of $2: 1$ is chosen. The final design parameters for the test fixture are then an inner and outer loading ring diameters of $D_{1}=8 \mathrm{~mm}$ and $\mathrm{D}_{2}=16 \mathrm{~mm}$, respectively, for square specimens of edge length of at least $20 \mathrm{~mm}$ and thickness of $0.7 \mathrm{~mm}$.

The stress state in a sample loaded by coaxial rings is biaxial and constant on the surface directly opposite the inner loading ring and has a value given by ${ }^{9}$

$$
\sigma_{\max }=\frac{3 P}{4 \pi t^{2}}\left[2(1+v) \ln \left(\frac{D_{z}}{D_{1}}\right)+(1-v)\left(\frac{D_{z}^{2}-D_{1}^{2}}{D_{3}^{2}}\right)\right]
$$

where $v$ is Poisson's ratio of the sample.

Loading Ring Yield: There is also concern that the polymer loading rings could yield when very high loads are applied, e.g., for specimens which are especially strong and thick. For a $1 \mathrm{~mm}$ ring width, the expected compressive stress in the upper loading ring would exceed the compressive yield strength of the acetyl polymer ring only when the strength of the specimen exceeds $1 \mathrm{GPa}$ and the specimen thickness is in excess of $1.17 \mathrm{~mm}$. Both of these values are much greater than the expected specimen parameters.

\section{EXPERIMENTAL}

\section{Material Compositions}

Evaluation of AlN materials was performed on three materials, identified as AlN - 0, AlN - 1 and AlN - 2, each supplied by Toshiba Corp. AlN - 0 was identified as a commercial material produced from a direct nitrided AlN powder

Certain commercial materials are identified in order to adequately specify the experimental procedure. Such identification does not imply recommendation or endorsement by the National Institute of Standards and Technology, nor does it imply that the materials or equipment identified are necessarily the best available for the purpose. 
and $3 \mathrm{wt} \% \mathrm{Y}_{2} \mathrm{O}_{3}$ as a sintering additive and was representative of current production. The AIN - 1 and AlN -2 materials were prototype materials. Each used Dow 35548 AlN powder, a material produced by carbothermal reduction. The AlN - 1 material was fabricated using the same dopant chemistry $\left(3 \mathrm{wt} \% \mathrm{Y}_{2} \mathrm{O}_{3}\right.$ ) and similar sintering conditions as the reference material. The AlN - 2 materials contained a complex dopant package ( $3 \mathrm{wt} \% \mathrm{Y}_{2} \mathrm{O}_{3}, 1 \mathrm{wt} \% \mathrm{CaCO}_{3}, 0.25 \mathrm{wt} \%$ $\mathrm{LaB}_{6}$, and $0.3 \mathrm{wt} \% \mathrm{WO}_{3}$ ), which was formulated for sintering at much lower temperatures.

\section{Testing Conditions}

The mechanical properties of each material in the as-received condition were evaluated in biaxial flexure using a coaxial ring fixture with acetyl polymer rings of nominal 8 and $16 \mathrm{~mm}$ diameters. The samples were equilibrated in flowing dry nitrogen atmosphere for at least 5 minutes then stressed at approximately 20 $\mathrm{MPa} / \mathrm{s}$, except as noted. Loads were measured with a $1000 \mathrm{~N}$ load cell which was calibrated using dead weight loading in $100 \mathrm{~N}$ increments from 100 to $500 \mathrm{~N}$ prior to testing. The maximum deviation from linearity within this range was $0.2 \mathrm{~N}$, yielding an error of less than $0.1 \%$ for the load range employed. Specimen thickness was measured using a micrometer to $2 \mu \mathrm{m}$ after testing, yielding a possible error of $0.6 \%$ in strength based on a nominal $0.7 \mathrm{~mm}$ sample thickness. Errors in the determination of ring diameters would be expected to result in errors of less than $0.35 \%$ in the stress level. Calculation of stress required a value for Poisson's ratio. A value of 0.23 was used for the calculations. A maximum error in calculated stress of $2.2 \%$ would result if the true value of Poisson's ratio were between 0.19 and 0.27 .

\section{Strength}

Strength variations in nominally identical samples of brittle materials are typically described in terms of the Weibull distribution, based on extreme value statistics. ${ }^{17}$ The two-parameter Weibull distribution employs an equation of the form:

$$
P=1-\exp \left[-\left(\frac{\sigma_{i}}{S_{0}}\right)^{m}\right]
$$

where $\mathrm{P}$ is the probability of failure, $\mathrm{S}_{0}$ the characteristic strength (scale parameter) and $\mathrm{m}$ is the Weibull modulus (shape parameter). 
The Weibull modulus was evaluated in biaxial flexure for all three materials in the as received state. The samples were tested in dry $\mathrm{N}_{2}$ at loading rates of approximately $20 \mathrm{MPa} / \mathrm{s}$. Approximately 30 samples of each material were tested for estimation of Weibull modulus. The Weibull modulus was calculated using a maximum likelihood technique with an unbiasing factor to account for the number of samples tested. ${ }^{18}$ The data are plotted using order statistics. If a series of $n$ samples are tested and the strengths of the samples are ordered from lowest to highest, the probability of failure of the $i^{\prime}$ th strength $\mathrm{P}_{\mathrm{i}}$ is approximated by: ${ }^{18}$

$$
P_{i}=(i-0.5) / n
$$

A plot of $\ln \ln \left[1 /\left(1-\mathrm{P}_{\mathrm{i}}\right)\right]$ against $\ln \left[\sigma_{\mathrm{i}}\right]$ should give a straight line of slope $\mathrm{m}$ and an intercept of $-\mathrm{m} \ln \left[\mathrm{S}_{0}\right]$, when a single flaw population exists in the sample.

Limited numbers of samples were examined with optical microscopy to determine the failure origin and to assure that failure was not occurring either directly opposite the upper loading ring, as might be the case when contact stresses are mirrored on the tensile surface, or at the edges. In general, the approximate location of the failure origin could be located, but the flaw which resulted in failure could not be inconclusively identified. This, in large part, was due to the lack of large, strength limiting flaws such as pores or cracks.

AlN - O Strength: Evaluation of the Weibull Modulus of AlN - 0 gave an unbiased likelihood estimator of the Weibull modulus of 14.5 and characteristic strength of $403 \mathrm{MPa}$. The straight line behavior in the Weibull plot (Fig. 3) indicates that multiple flaw populations and failure mechanisms are probably not active. Fracture surfaces of selected samples were examined in the stereo microscope. At the limits of resolution of the stereo microscope (Fig. 4) it appeared that the failure might have originated at relatively small areas which might have been incompletely sintered or had a slightly different distribution of the second phase dopant; this conclusion, however, is preliminary and requires further investigation. For the samples of AIN - 0 which were examined, no edge failures were found and there did not seem to be a predominance of failures which initiated near the inner loading ring.

AlN - 1 Strength: Prior to testing, the AIN - 1 samples were examined for variations which might indicate changes in properties or difficulties in testing. As compared to the homogeneous, flat samples of AIN - 0 , some of the samples were 


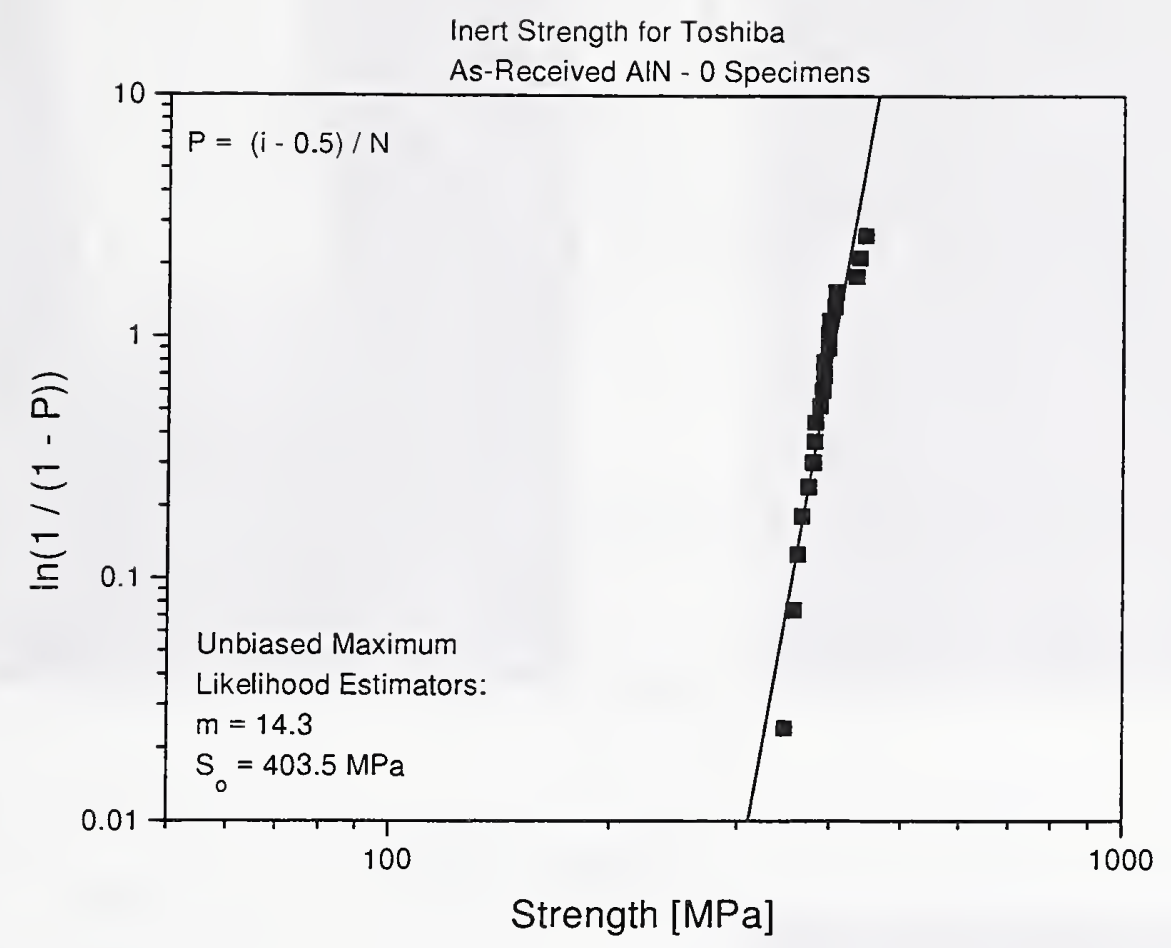

Figure 3 Weibull plot of AlN - 0 strength data.

clearly warped. Since the coaxial ring fixture was not designed to accommodate warped samples, it was felt that this warpage could affect the stress state, thus the measured strength. Two options existed: (1) either the samples could be sorted by degree of warpage and the least warped samples could be tested; or (2) the degree of warpage could be quantified, all of the samples could be tested and a correlation between measured strength and degree of warpage could be sought. Segregation of the samples by degree of warpage was rejected as censoring data could have biased the results. For example, density gradients in the unfired tape cast sample, which could cause warpage, would probably have also caused local grain size and porosity variations, either of which can affect strength. Therefore, the degree of warpage was quantified by measuring the ratio of the maximum caliper thickness to the true specimen thickness. (Fig. 5) After these measurements were completed, the strengths of the uncensored samples were measured. A scatter plot of the maximum warpage and strength is presented in Fig. 6. While there might be acorrelation of maximum warpage to strength, since some of the least warped samples have the highest and lowest strengths, and the most warped samples do not have the lowest strengths, it was felt that warpage 

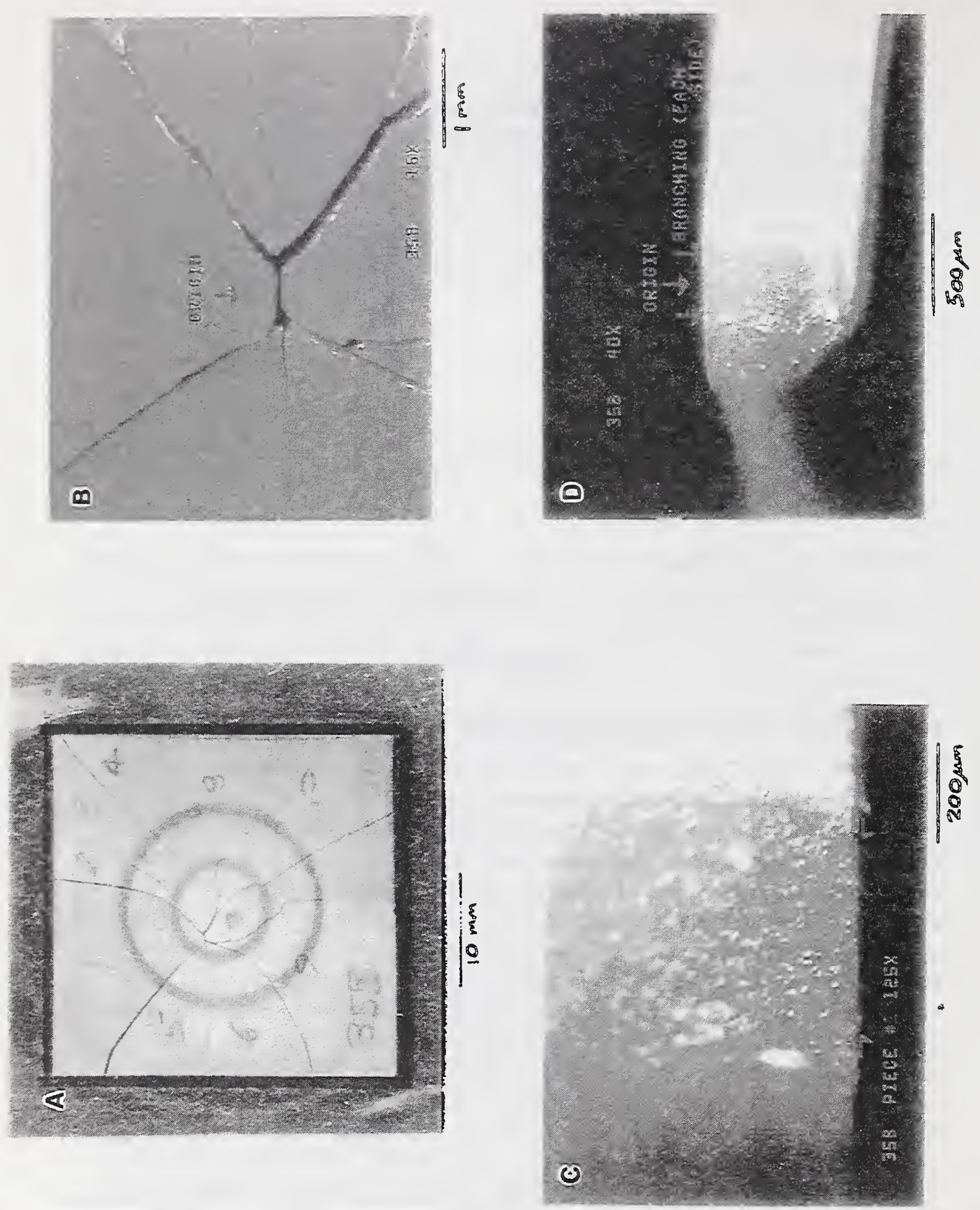

Figure 4. Fractographic analysis of a representative sample of AIN - 0. 


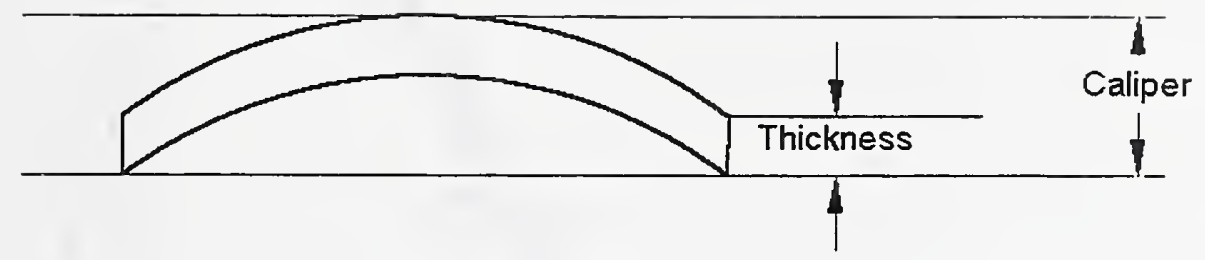

Warpage Measurement in Samples

Figure 5 Measurement of the degree of warpage in samples.

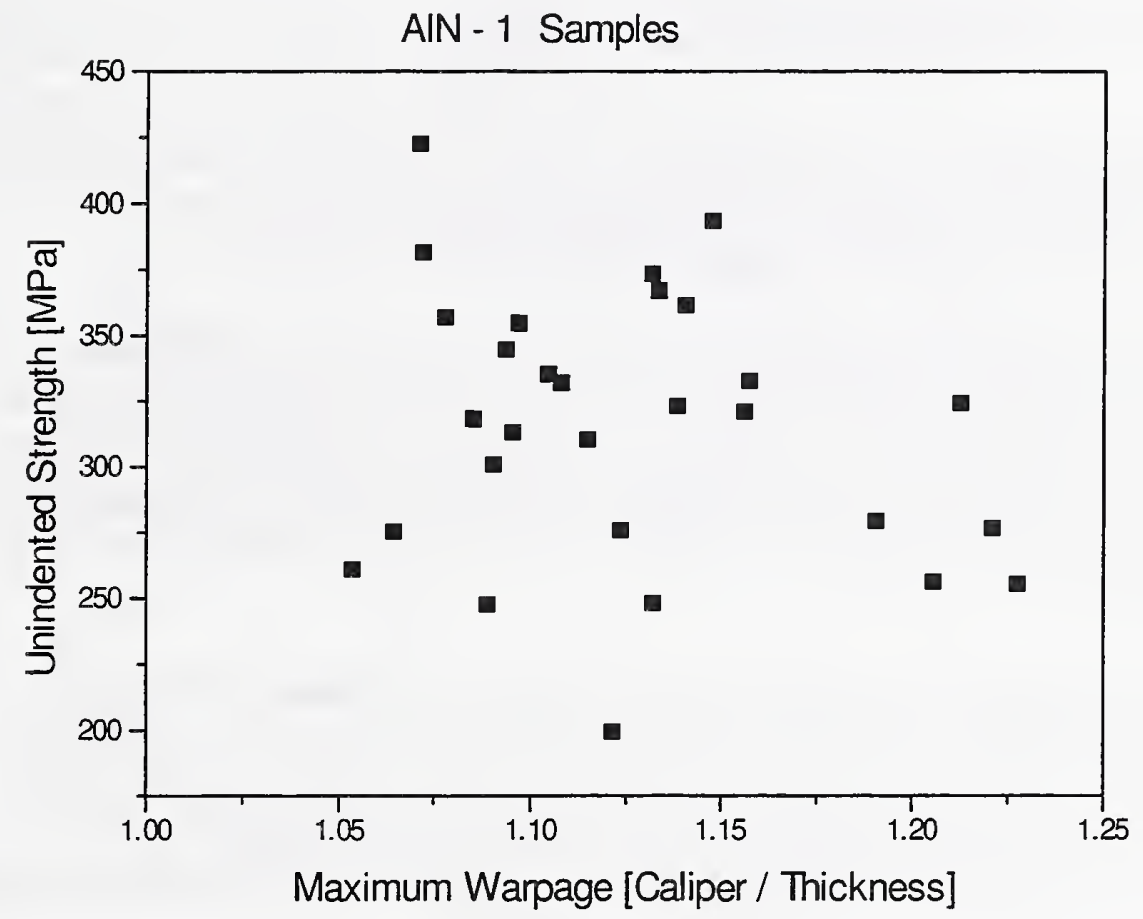

Figure 6. The strength of unindented AlN - 1 samples does not seem to correlate with the maximum specimen warpage. 


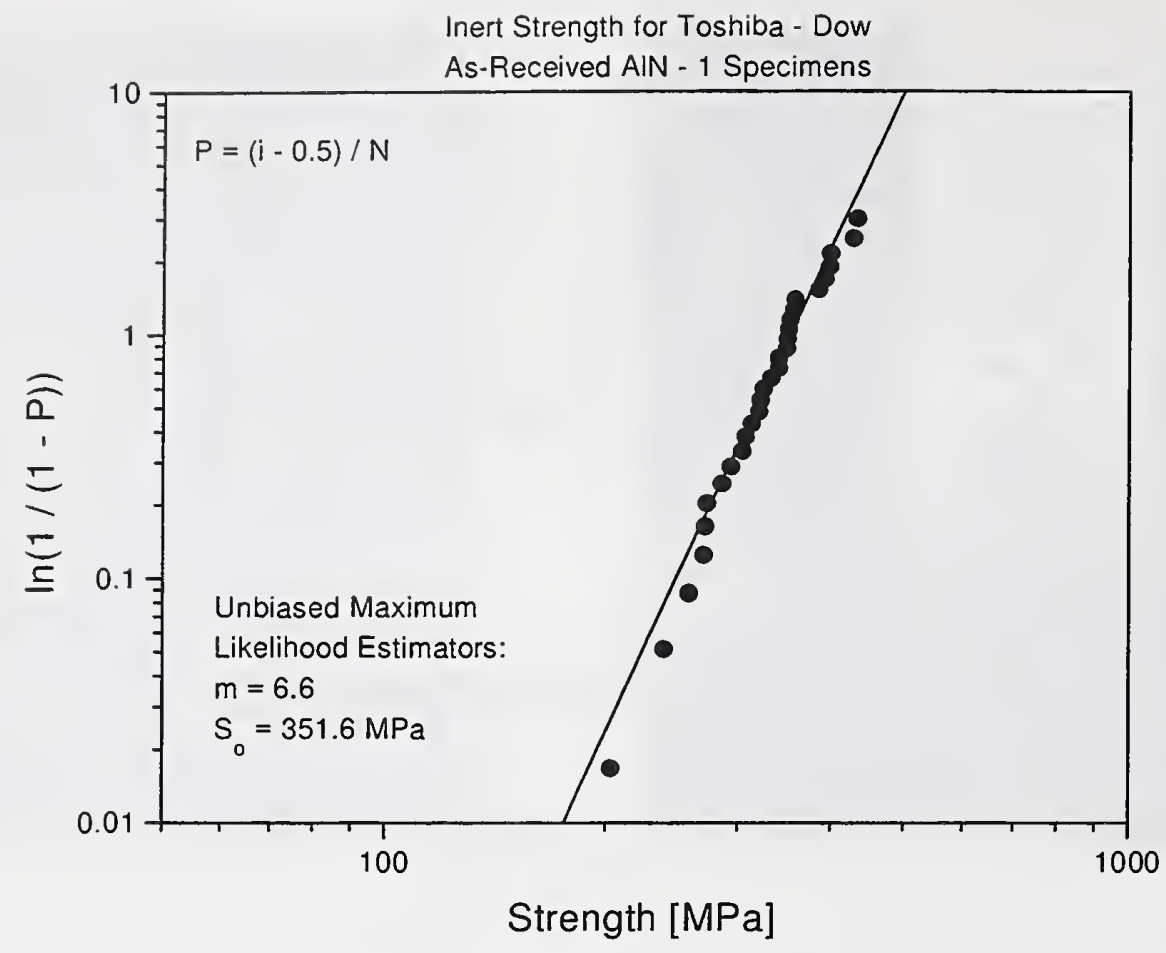

Figure 7. Weibull plot of the AlN - 1 strength data.

did not strongly influence the measurements. It should be noted, however, that the direction of warpage with respect to the fixture (e.g., concave up or concave down) was not evaluated and no correlation was made to strength.

Results of these strength measurements on AlN - 1 are given in a Weibull plot. (Fig. 7) As with the measurements on AlN - 0, the close fit to the straight line in the Weibull plot indicates that multiple flaw populations are probably not active in AlN - 1. The unbiased maximum likelihood estimate of the Weibull modulus is 6.6 with a characteristic strength of $352 \mathrm{MPa}$, both values significantly less than those for AlN - 0 .

In spite of the straight line behavior in the Weibull plot, indicative of a single active flaw population, visual examination of the AlN - 1 samples showed two distinct groups. While most of the samples were translucent with a slight greenblue color, some were much lighter in color, nearly white, and were opaque. A scatter plot of specimen strength and thickness (Fig. 8) shows that samples which 


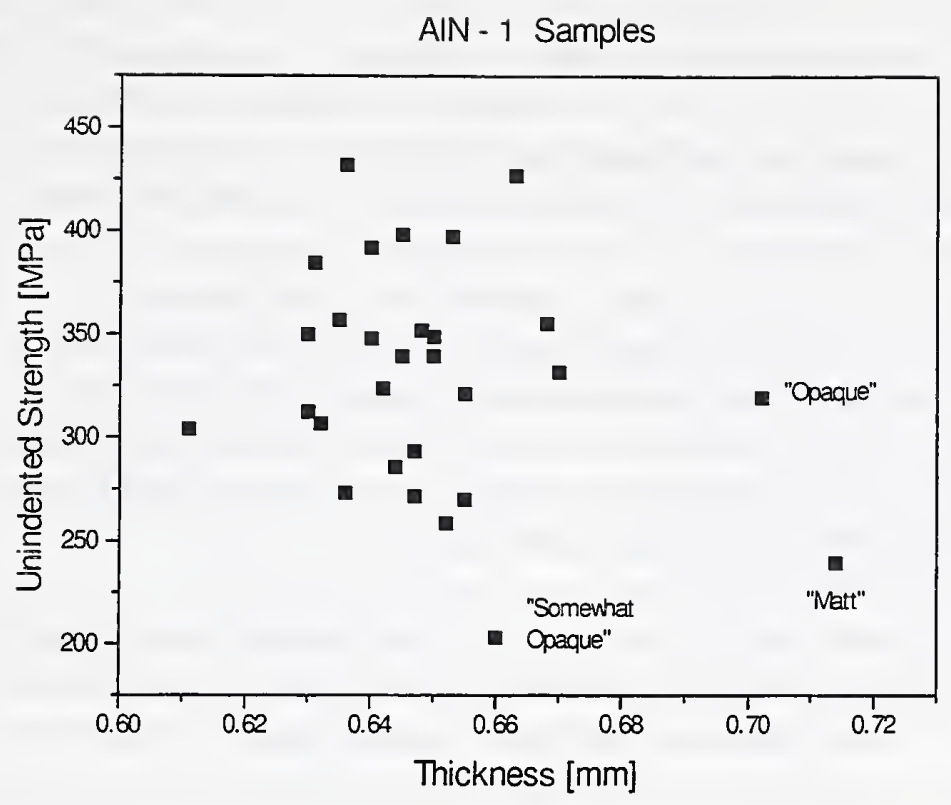

Figure 8. Most of the samples were translucent, except as noted. Thicker AlN - 1 samples seemed to have a lower strength than average and were opaque in appearance.

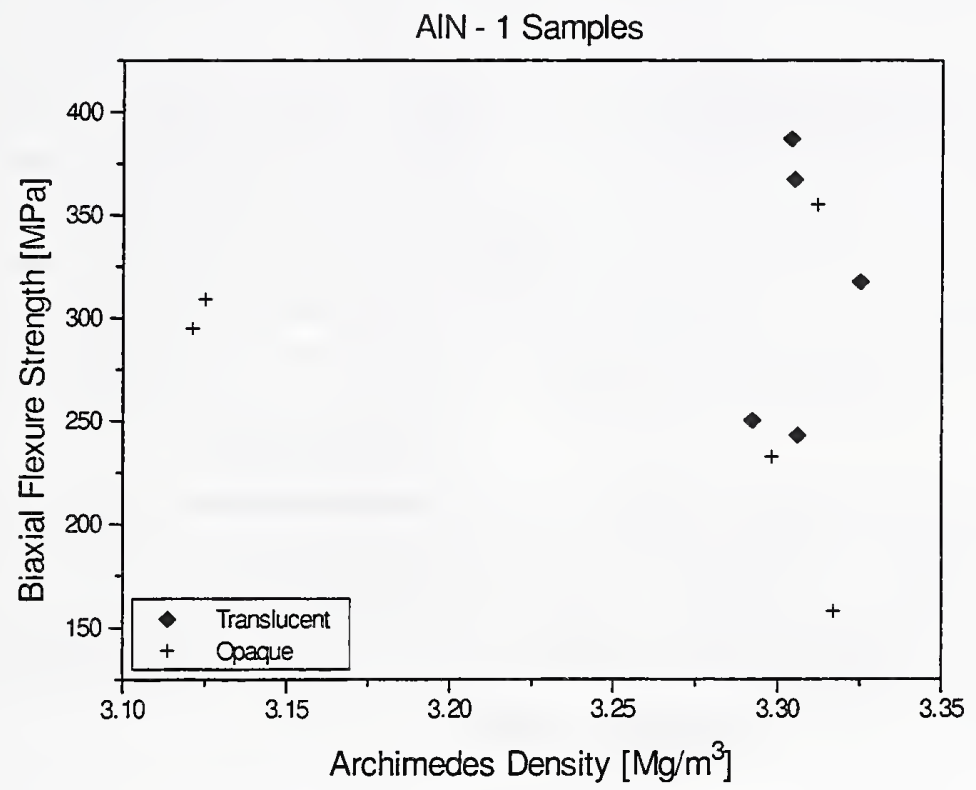

Figure 9. Strength and density of selected translucent and opaque AlN - 1 samples. 
were "opaque" or "matt" in appearance or were generally thicker and weaker than average. Since it was felt that both the opacity and increased thickness could be the result of samples which had a low sintered density, and this low density could result in low strengths, a series of samples, 5 of which were opaque and 5 of which were translucent, were randomly chosen from the remaining unbroken samples. The Archimedes densities of these samples were measured prior to measuring the strengths of these samples. A scatter plot of the measured strengths and densities of these two groups of samples is shown in Fig. 9. While the samples with the two lowest densities were opaque, the other three opaque samples had densities equal to those for the translucent samples. Further, the opaque sample with the lowest strength had a high density and the low density samples were not significantly weaker than average.

Since neither thickness, low density nor specimen color (opacity) were clearly correlated with variations in strength of the AlN - 1 samples, these data were included with the previously measured strength data in a Weibull plot. Figure 10 shows that the opaque specimens tend to be segregated to the lower strength

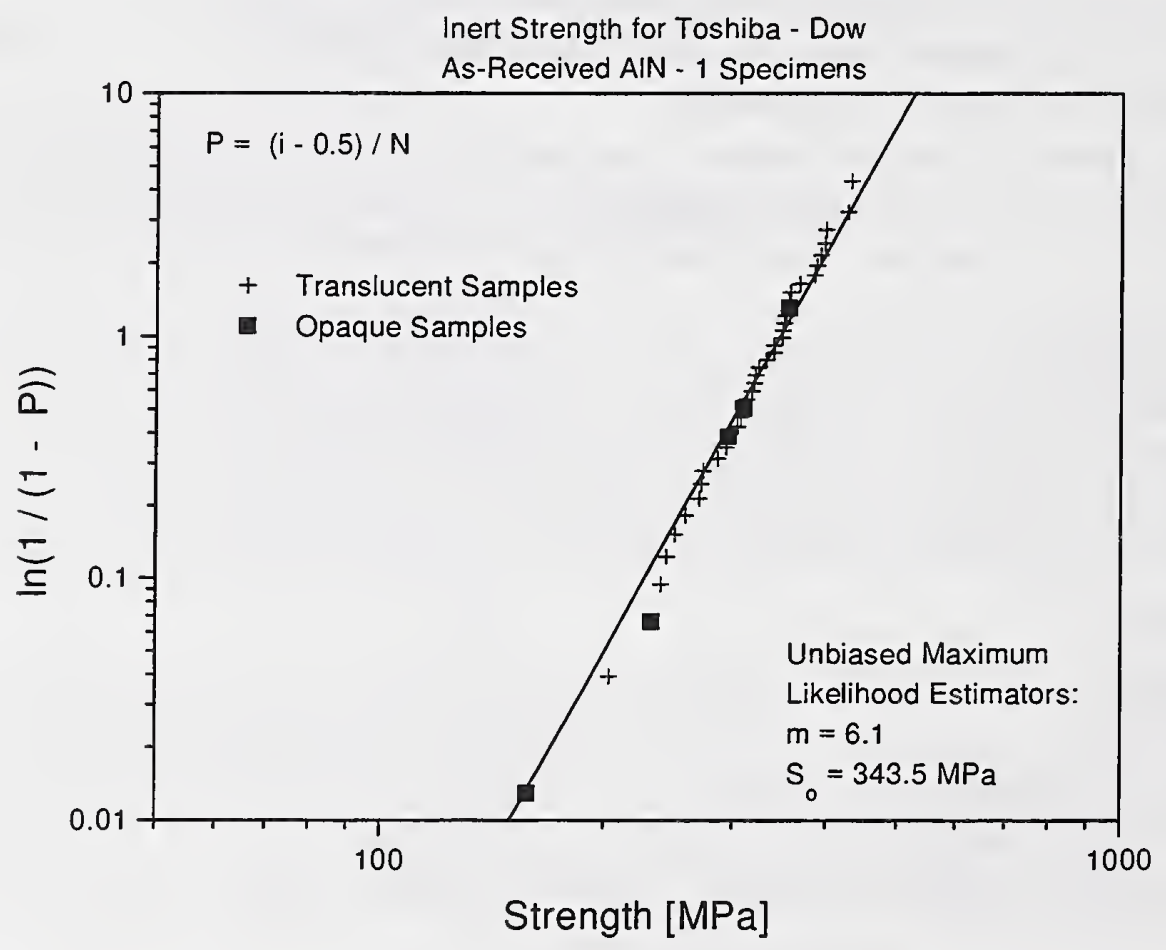

Figure 10 Weibull plot of translucent and opaque AlN - 1 samples. Note that the opaque samples tend to the bottom of the strength distribution. 
values and are not found among the strongest samples. Inclusion of the relatively large fraction of opaque samples ( 8 samples out of 40 as opposed to 3 out of 30 originally) decreases the Weibull modulus from 6.6 to 6.1 and the characteristic strength from 352 to $344 \mathrm{MPa}$. Although sufficient samples are not available for a full statistical analysis, it appears that the opaque samples may have different characteristics than the translucent samples.

As with examination of AlN - 0, fractographic analysis was able to determine the general failure origin but was not able to inconclusively determine the strength limiting flaw. Examination of the surface of the samples showed an irregularity in the surface finish of the sample which appeared to be small blisters or perhaps second phase which exuded from the sample during firing. (Fig. 11B.) Also, several small circular indentations could be found on the surface. (Fig. 11D.) These could have been a result of the lamination procedure which was employed to fabricate the samples. It should be reiterated that the actual strength limiting flaw could not be unambiguously identified and observation of either of these features could not be correlated with the failure origin.

AlN - 2Strength: The AlN - 2 samples were examined for variations in color and warpage prior to testing. Although these samples had a uniform base color, they had varying amounts of a second phase on the surface and the samples were even more warped than the AlN - 1 samples. As for the AlN - 1 material, there does not seem to be a correlation of strength with the degree of warpage. (Fig. 12) The scatter about the straight line in the Weibull plot (Fig. 13) indicates that there might be multiple strength populations. The unbiased maximum likelihood estimate of the Weibull modulus is 2.3 with a characteristic strength of $220 \mathrm{MPa}$, both values significantly less than those of AlN - 0 and AlN - 1. Fractography showed various pits on the surfaces (Fig. 14A, C, D) and what appeared to be a porous layer or layer denuded of second phase about $35 \mu \mathrm{m}$ in thickness at the surface (Fig. 14B). The combination of these artifacts may have been responsible for the relatively poor performance of the $\mathrm{AlN}-2$ samples.

Comparison: Comparison of the strength distributions of all three materials is given in Figure 15. The various rankings between the three materials is quite clear, with high Weibull modulus for AlN - 0 and AlN - 1, and a wider spread in strengths corresponding to a lower Weibull modulus for AlN - 2. Of particular 

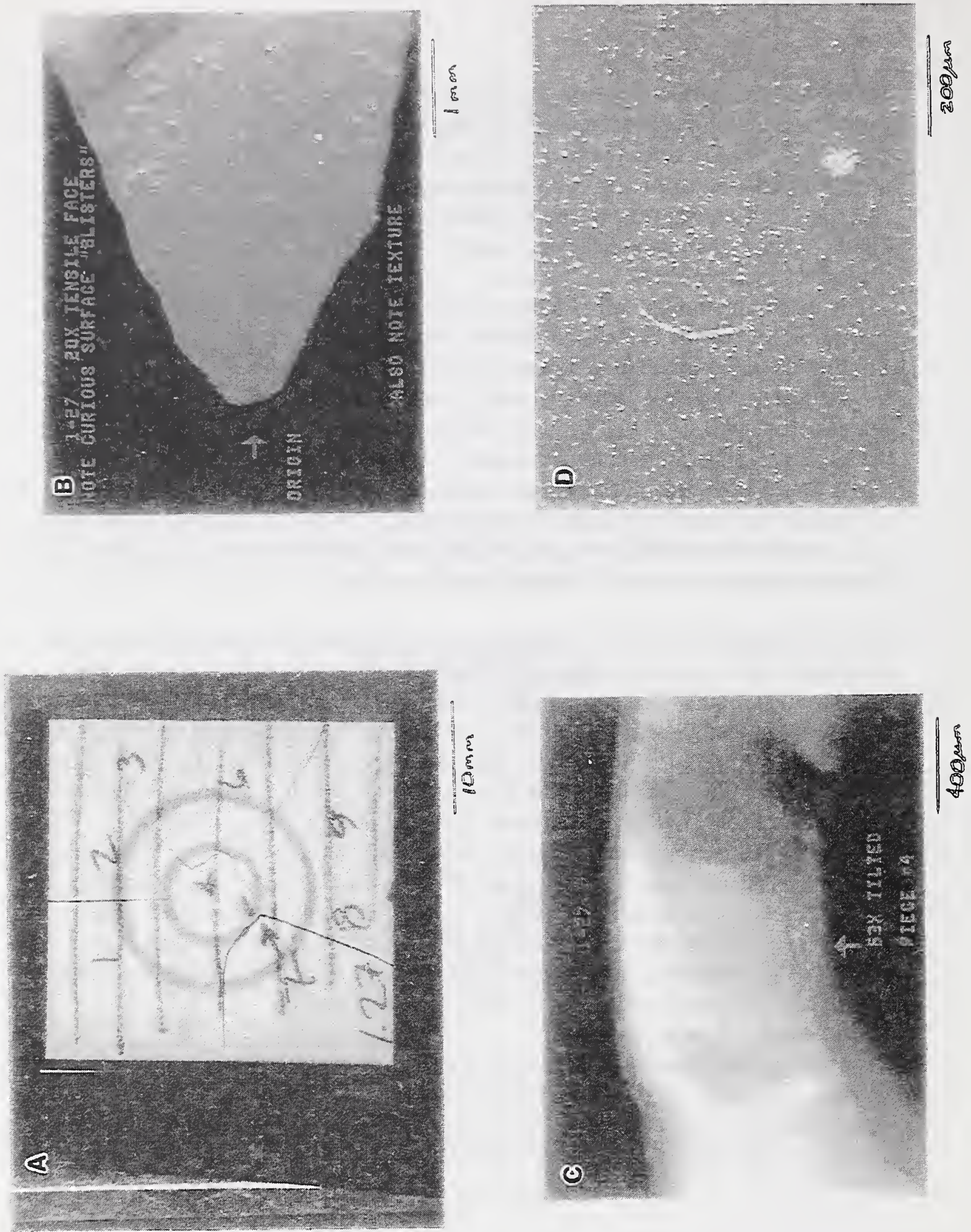

Figure 11. Fractographic analysis of AIN - 1. 


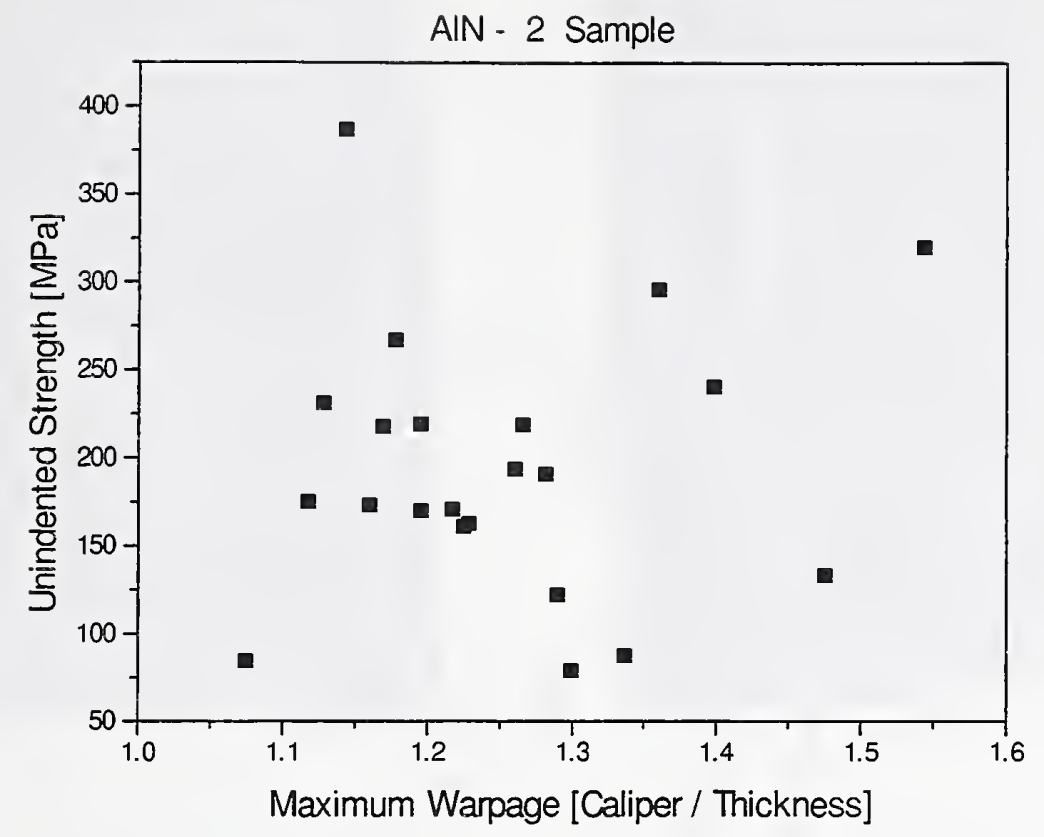

Figure 12. Specimen strength does not seem to correlate with maximum warpage.

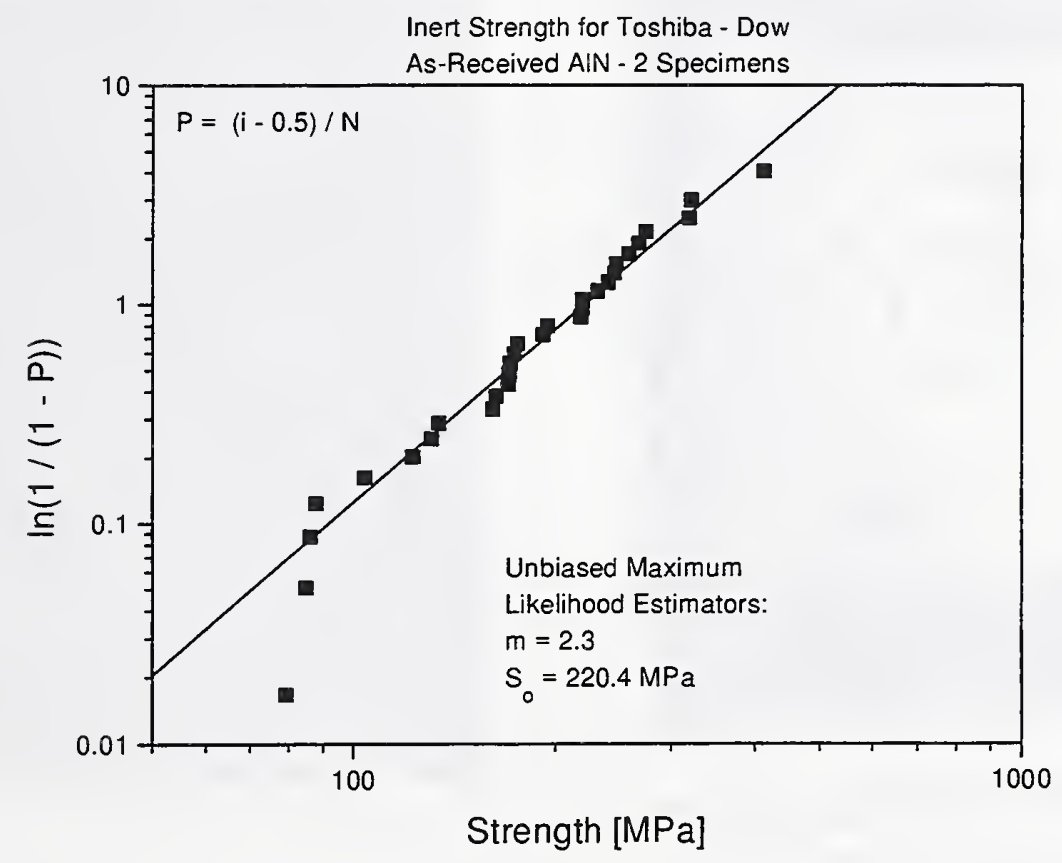

Figure 13. Weibull plot of AlN - 2 strength data. 

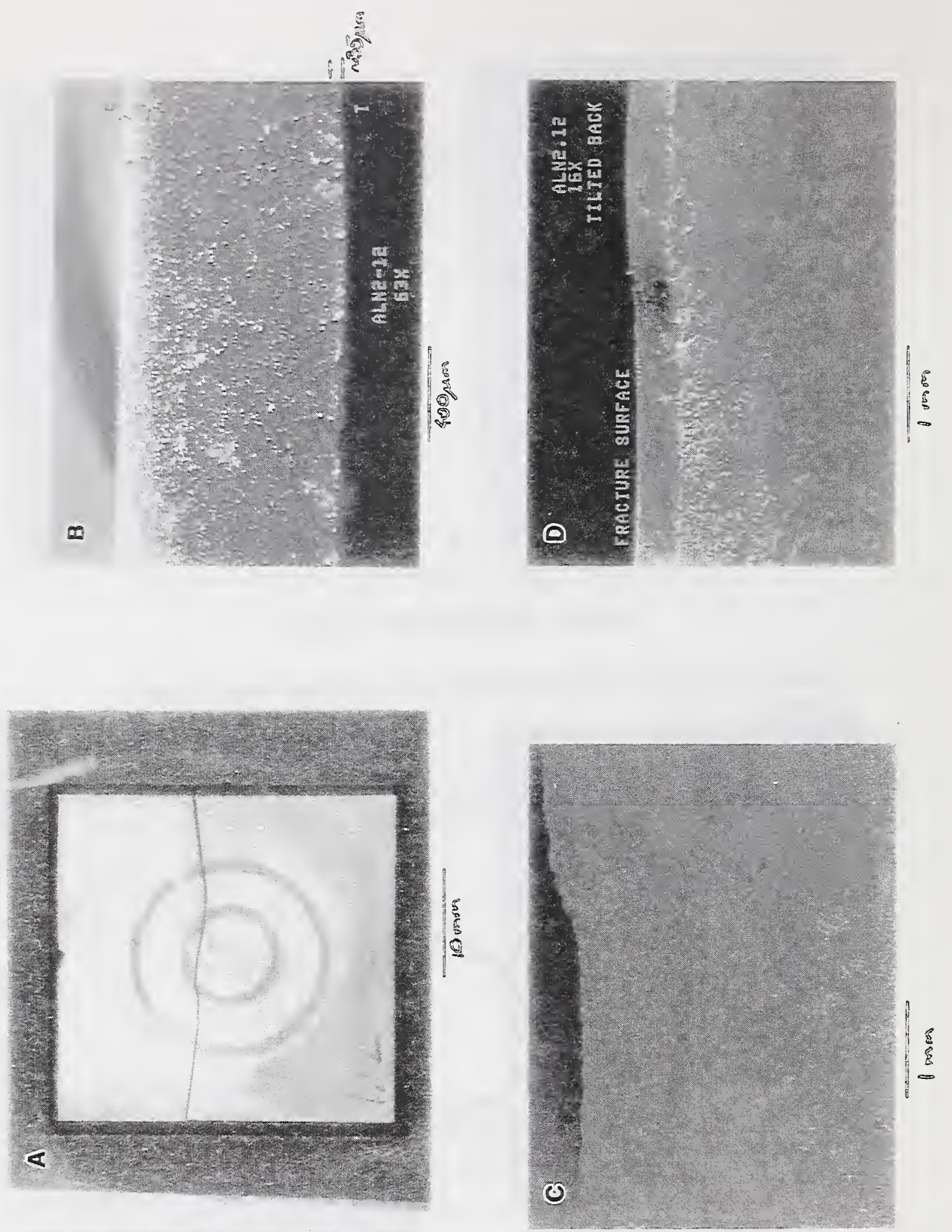

Figure 14. Fractography of AIN - 2. 
interest are the strongest samples of AlN - 0 and AlN - 1; there is considerable overlap in the strengths, indicating that there may be no inherent difference in the properties of the two materials.

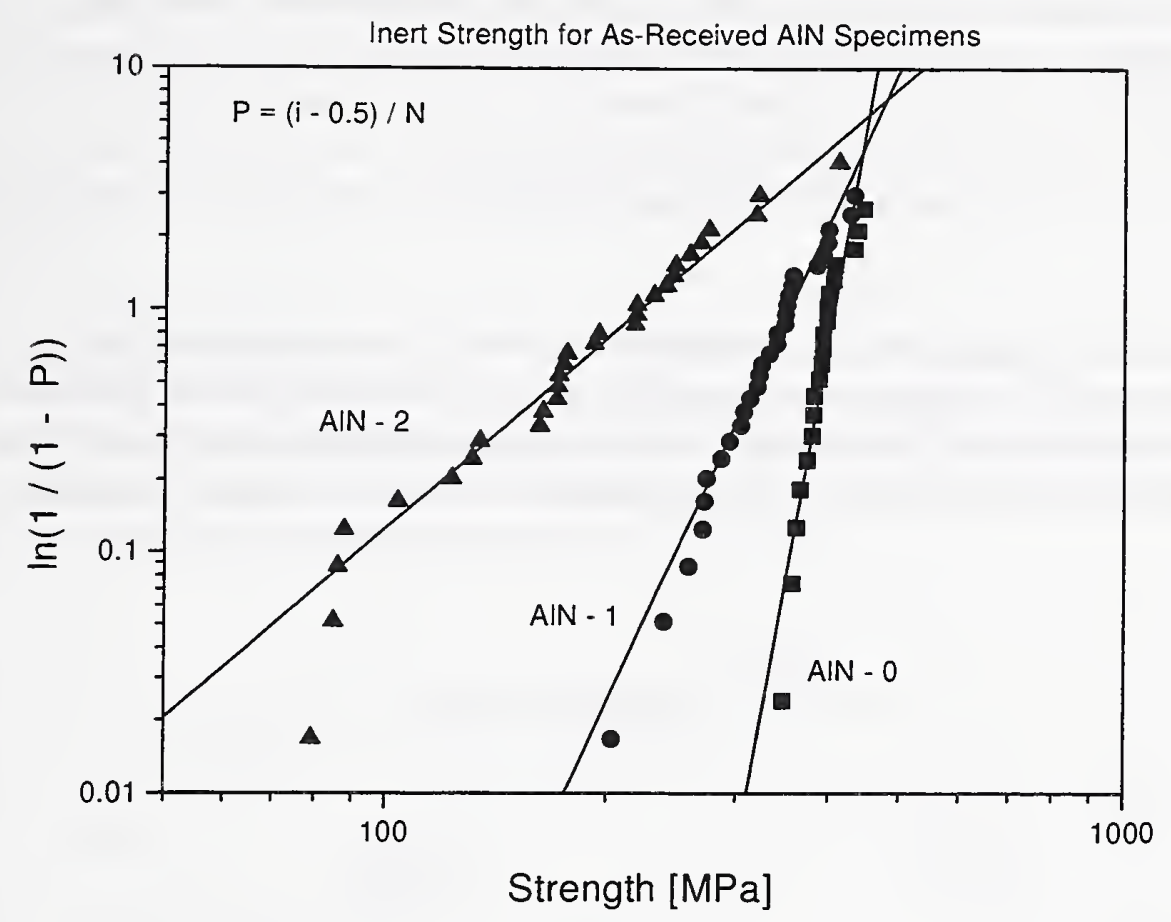

Figure 15. Comparison of the strength distributions of all three AlN materials.

\section{Toughness}

For brittle materials, the strength is composed of two primary factors: (1) flaw tolerance or toughness and (2) the severity of the strength controlling flaw. As changes in processing and microstructure may influence each of these two parameters independently, measurement of toughness, by means of the strength of a sample with a controlled flaw, is of utility. The technique chosen for this study is indentation strength in bending (ISB), in which a controlled flaw is introduced into the sample through the use of a Vicker's diamond indenter and the indented sample is then broken. The indentation process was evaluated theoretically by 
Anstis et al. ${ }^{19}$ and the ISB technique was evaluated experimentally by Chantikul et $a l .{ }^{20}$ It has been shown that, for brittle materials, when a range of indentation loads are employed, well developed median cracks develop at the corners of the Vickers indent and in the absence of R-curve effects (increasing resistance to crack extension with increasing crack length), a plot of indentation load and fracture strength, both on logarithmic scales, should yield a straight line of slope $-1 / 3$. If the $-1 / 3$ slope criterion is fulfilled, the fracture toughness can be calculated using the equation:

$$
K_{1 c}=\eta\left(\frac{E}{H}\right)^{1 / 8}\left(\sigma, P_{i}^{1 / 3}\right)^{3 / 4}
$$

where $\mathrm{E}$ is the Young's modulus ( $308 \mathrm{GPa}$ for $\mathrm{AlN}^{15}$ ), $\mathrm{H}$ is the material hardness (12 GPa for $\left.\mathrm{AlN}^{21}\right), \sigma_{\mathrm{f}}$ is the strength of the specimen indented with a Vickers indenter with a load of $P_{i}$ and $\eta$ is an ISB calibration constant which has a value tabulated in the literature of $0.62 .{ }^{20}$ On each of the indentation load - strength

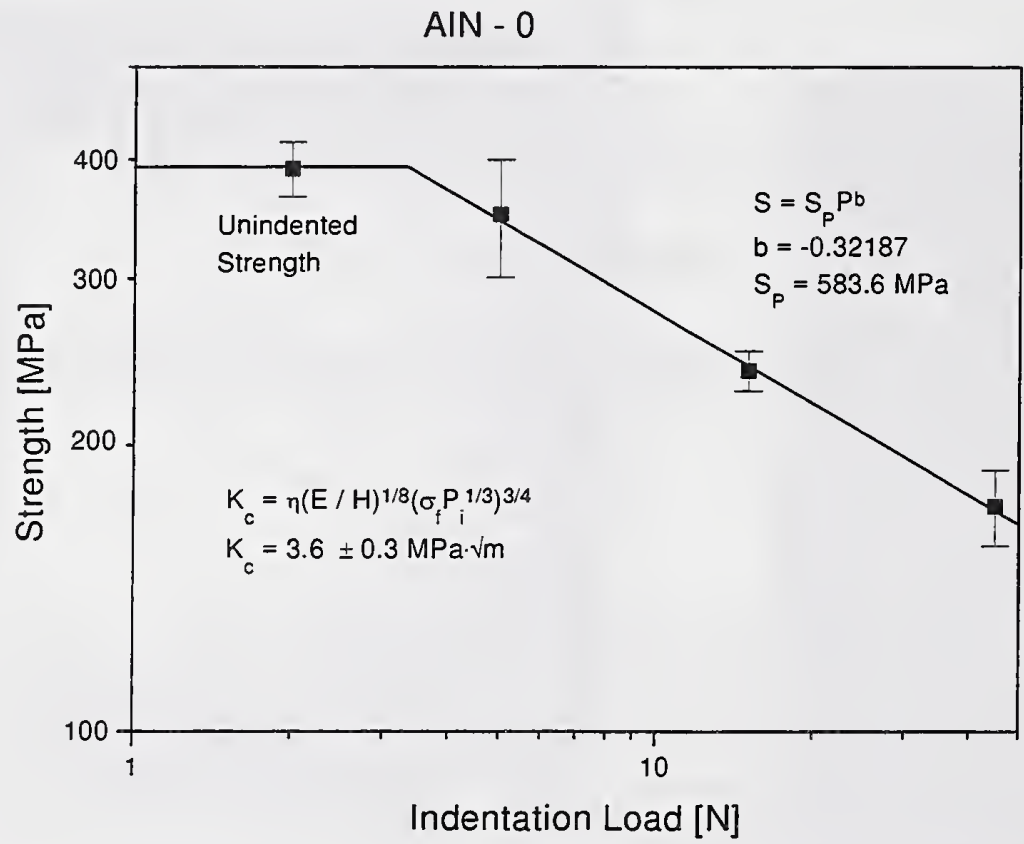

Figure 16. The indentation strength in bending gave a toughness value of $3.6 \mathrm{MPa} \cdot \sqrt{\mathrm{m}}$. 
plots, a data point for unindented strength and a horizontal line through it is also included. The intersection of this line and the regression line represents the indentation load needed to produce a Vicker's indent which has a severity similar to that of the intrinsic flaws in the material. The toughness value reported are the average of the individual $\mathrm{K}_{\mathrm{IC}}$ values calculated using Eq. 4 .

AlN - O Toughness: Results of ISB measurements on AIN - 0 are shown in Fig. 16. The regression line for data from indentation loads greater than $4 \mathrm{~N}$ shows a slope of -0.32 , in good agreement with the theoretical value of $-1 / 3$. The calculated average value of $\mathrm{K}_{\mathrm{IC}}$ from the three largest indentation loads is $3.6 \pm 0.3 \mathrm{MPa} \cdot \sqrt{\mathrm{m}}$. The straight line behavior also indicates that AlN - 0 does not exhibit any R-curve behavior.

AlN - I Toughness: We have noted previously that AlN - 1 samples could be separated into two groups on the basis of appearance, translucent and opaque. The ISB data has also been separated into these two groups. For the translucent samples, the regression line for the four highest indentation loads had a slope of -0.25 , somewhat less than the expected value of $-1 / 3$.

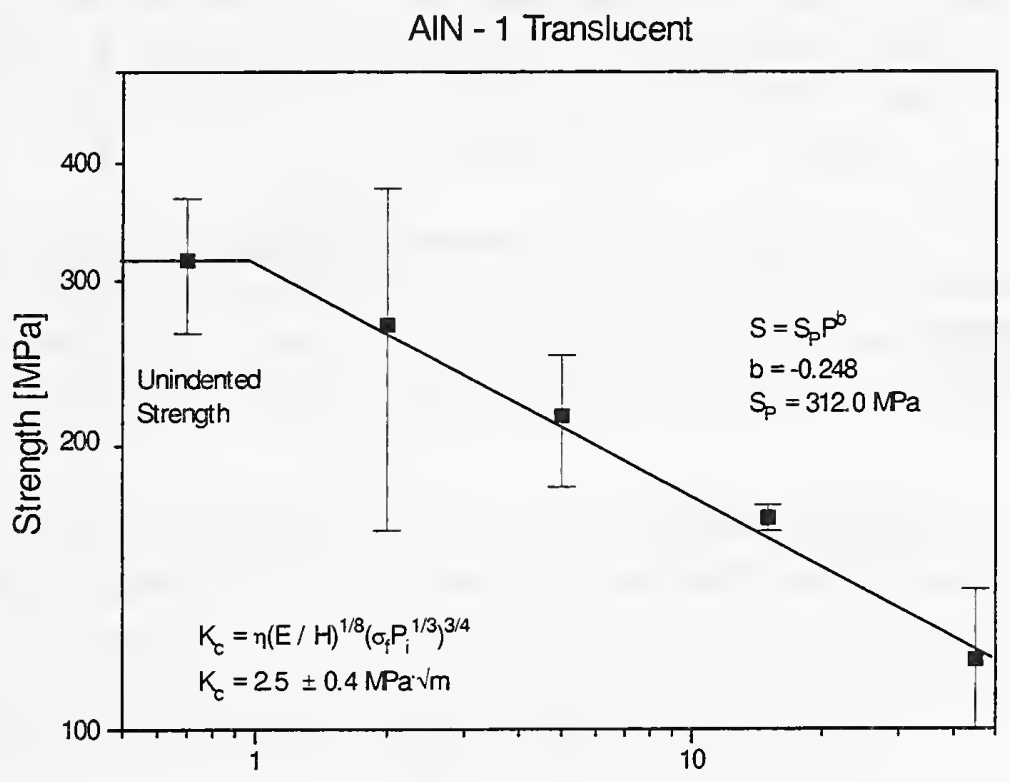

Figure 17. The measured ISB toughness for translucent AIN - 1 was $2.5 \mathrm{MPa} \cdot \sqrt{\mathrm{m}}$. 
The lower than expected slope could be the result of R-curve behavior. However, as none of the other samples seemed to exhibit R-curve behavior, a more likely explanation the large overlap in the strength data of the unindented samples and those indented at $2 \mathrm{~N}$. (Fig. 17) Apparently the flaws produced by the $2 \mathrm{~N}$ Vickers indents were only slightly more severe than the naturally occurring flaws in the material. Without these $2 \mathrm{~N}$ indent data, the slope is -0.28 , somewhat closer to the expected $-1 / 3$ value. Using these data, that calculated fracture toughness is $\mathrm{K}_{\mathrm{IC}}=$ $2.5 \pm 0.4 \mathrm{MPa} \cdot \sqrt{\mathrm{m}}$, significantly less than the value of $3.6 \mathrm{MPa} \sqrt{\mathrm{m}}$ measured for $\mathrm{AlN}-0$.

If we invoke linear elastic fracture mechanics and assume that the flaw population in AlN - 0 and translucent AlN - 1 are similar, any changes in fracture toughness between the two materials should be proportionately reflected in the strengths of the samples; we would expect a decrease in strength of $31 \%$ from that of the AlN - 0 samples. Taking the characteristic strengths of from the Weibull modulus determinations, 403 and $351 \mathrm{MPa}$, respectively, we find a measured strength

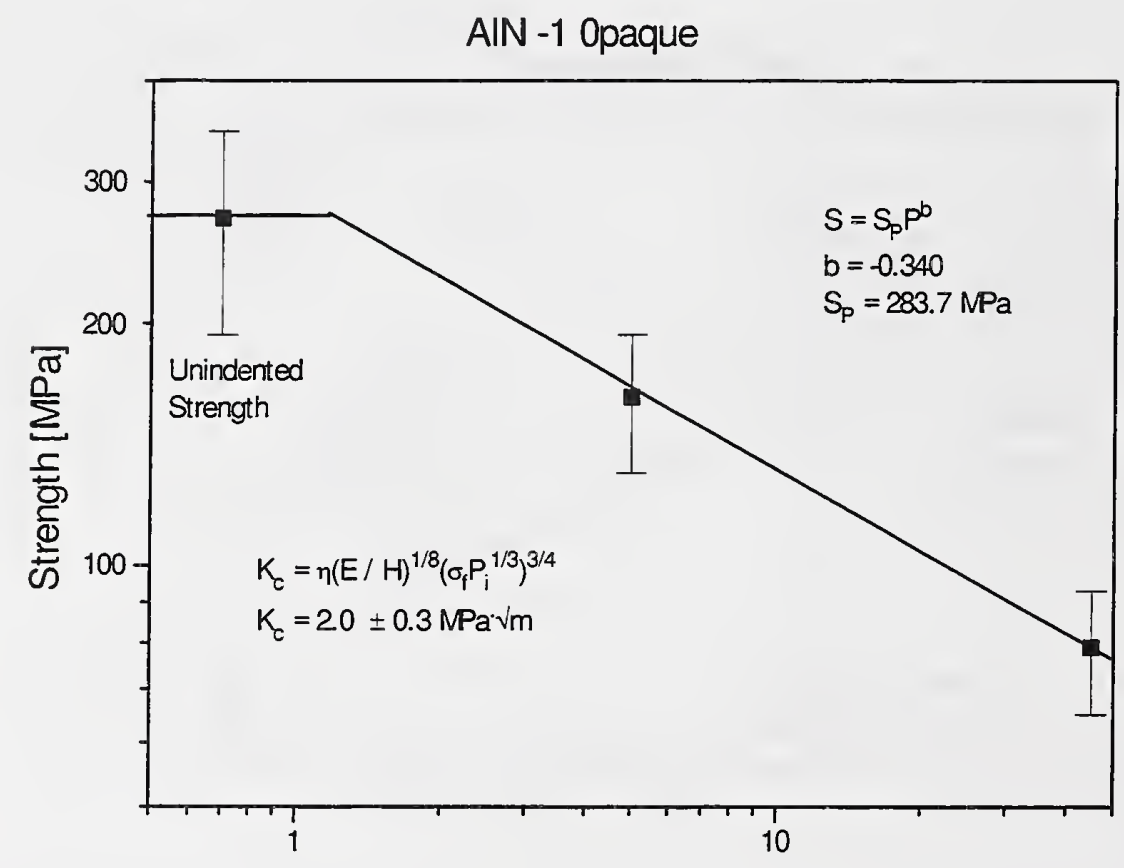

Figure 18. The measured toughness was $2.0 \mathrm{MPa} \cdot \sqrt{\mathrm{m}}$. 
decrease of $13 \%$. Since the actual strength decrease is less that expected from changes in toughness, the flaws leading to failure in the translucent AlN - 1 samples appear to be less severe than those in AlN -0 . The relatively high density of the AlN - 1 samples, as evidenced by the translucency, would imply that there are relatively few features such as pores and cracks, which not only scatter light but could also act as flaws. A more quantitative measurement such as density comparisons is desirable but, as will be discussed, although the dopant system and amounts of dopant for AlN - 0 and translucent AlN - 1 are the same, the crystalline second phases are significantly different. Therefore, direct comparison of Archimedes densities would not yield meaningful information. It is interesting to note, however, that the variability in Archimedes density in each the two sets of samples, as measured by the respective standard deviations, seems to mirror the variability in strengths, as measured by Weibull modulus. (Table I)

The regression line through the data for the opaque AlN - 1 material fit the expected $-1 / 3$ slope quite well. (Fig. 18.) The calculated average toughness was $\mathrm{K}_{\mathrm{IC}}=2.0 \pm 0.3 \mathrm{MPa} \cdot \sqrt{\mathrm{m}}$, less than that for either AlN - 0 or translucent AlN - 1 . Within the scatter of the data, it is not clear that there is a statistically significant difference between the translucent and opaque samples of AlN - 1. As a result, it is not possible to determine if the lower unindented strength in opaque AlN - 1 samples, as compared to the translucent AlN - 1, is a result of changing fracture toughness or changing flaw population. The data showed clearly, however, that there is a significant difference in materials properties between AlN - 0 and AlN - 1. The reasons for these differences were not apparent.

AlN - 2 Toughness: ISB measurements on AlN - 2 also showed the expected behavior, with the regression line slope of -0.31 . (Fig. 19.) The average toughness determined from the data is $\mathrm{K}_{\mathrm{IC}}=2.4 \pm 0.3 \mathrm{MPa} \cdot \sqrt{\mathrm{m}}$, similar to the values measured for both groups of AlN - 1 material but significantly different than that for AlN - 0.

As opposed to the behavior of AlN - 1, the decrease in strength in these samples, as compared to AlN - 0, was greater than that which would be expected from toughness changes alone; clearly the flaw population was also changing. This is also supported by the relatively low Weibull modulus and fractographic evidence of changing microstructure near the surface of the samples. 


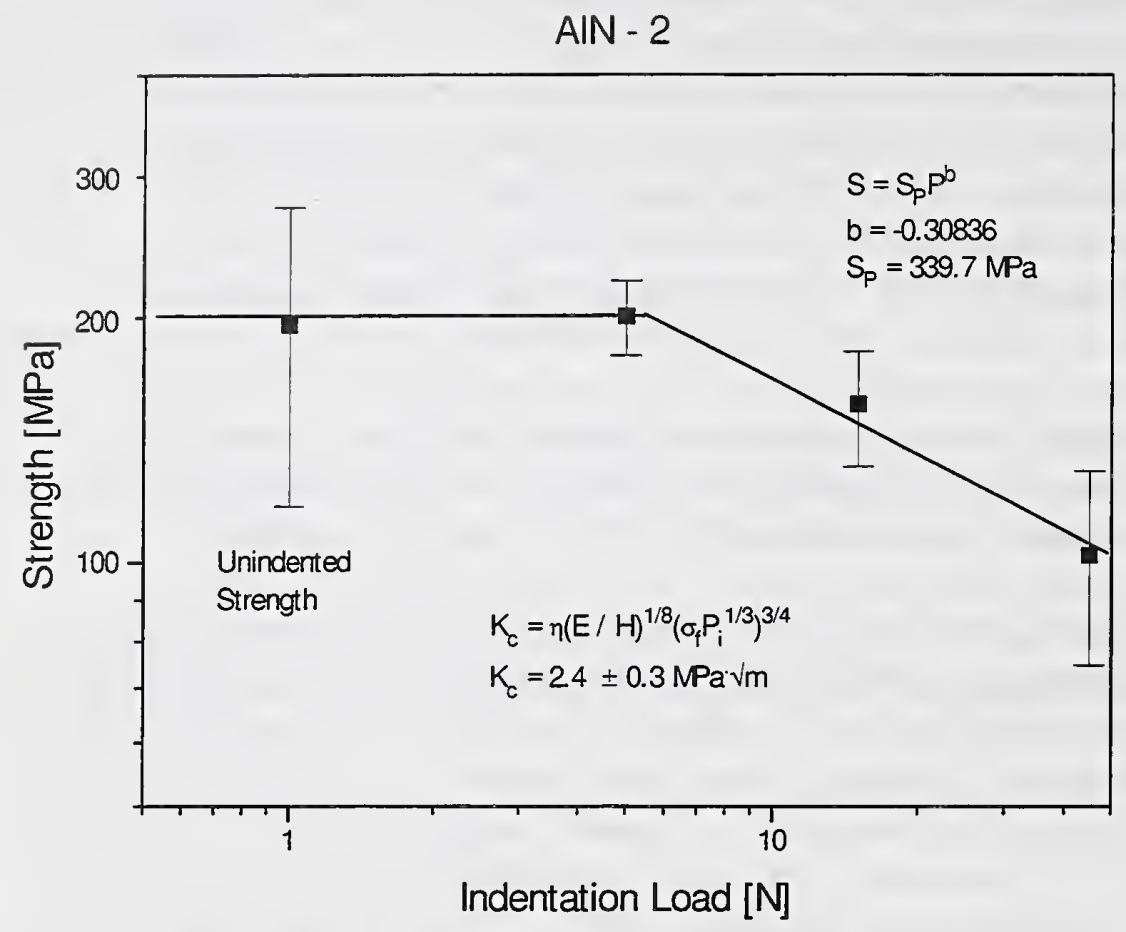

Figure 19 The measured ISB toughness for AlN - 2 was $2.4 \mathrm{MPa} \cdot \sqrt{\mathrm{m}}$.

\section{Dynamic Fatigue}

Reliability of materials in service not only involves survival during short time, high load conditions, such as impact loading, but also survival over long time periods at loads which would not cause failure during short times. Since the failure is time dependent, it is a thermally activated process. Frequently, this is a combination of stress fields in the sample with external chemical agents such as moisture in the air. For indented samples with a residual stress at the indent ${ }^{22} \mathrm{a}$ mathematical description of the reduction in fracture strength for long-term constant stress, static fatigue, loading is: ${ }^{23}$

$$
\sigma_{f}=\left[\frac{B^{\prime} S^{N_{-2}}}{t_{j}}\right] \frac{1}{N^{\prime}}
$$


where $\mathrm{S}$ is the short-term strength, $\mathrm{t}_{\mathrm{f}}$ is the time to failure at the applied stress $\sigma_{\mathrm{f}}$, $\mathrm{B}^{\prime}$ is a term describing crack growth conditions, and $\mathrm{N}^{\prime}$ is a residual stress modified crack growth exponent. Rearranging to obtain an expression for $t_{f}{ }^{23}$

$$
t_{,}=B^{\prime} S^{N^{\prime}-2} \sigma_{,}{ }^{\prime}
$$

If a distribution in fracture strength exists and the samples are loaded to the same stress level, as N' becomes large ( $>50)$ the time to failure can vary greatly. For example, if a given sample is loaded to $90 \%$ of its short time failure stress, the time needed for failure to occur increases by a factor of 200 for an N' of 50 and by a factor of 37,650 for $N^{\prime}$ of 100 . The wide range of times to failure can become an experimental difficulty when experiments are to be carried out in finite times.

An alternate approach, which avoids the possibility of extremely long testing times, is to load the indented samples at a constant stressing rate, do/dt, until failure occurs. The dynamic fatigue failure strength is then given by ${ }^{23}$

$$
\sigma_{f}=\sigma_{0}\left[\frac{1}{\dot{\sigma}_{o}} \frac{d \sigma}{d}\right]^{\frac{1}{N^{\prime}-1}}
$$

where $\sigma_{\mathrm{f}}$ is the measured fracture strength for a stressing rate $\mathrm{d} \sigma / \mathrm{dt}$ and $\sigma_{0}$ is the strength at a reference loading rate of $\dot{\sigma}_{o}$, taken here as $1 \mathrm{MPa} / \mathrm{s}$. Since the load on the sample is constantly increasing until failure occurs, failure is assured in reasonable times, depending on the stressing rate. Further, it has been shown that rapidly preloading samples to $70 \%$ of the expected failure stress, effectively reduces the total test time by $70 \%$, yet has minimal effect on the final failure stress and $\mathrm{N}^{\prime}$ value. ${ }^{24}$ For practical reasons concerning the ability to obtain adequate sampling statistics in the time frame available, this dynamic fatigue technique was chosen for testing the AlN samples.

For a displacement-controlled testing machine the stressing rate can be varied over 5 orders of magnitude by using a combination of varying the cross-head speed and employing a high compliance base for the coaxial ring fixture. Testing times can be varied from approximately $1 \mathrm{~s}$ without a preload to $15 \mathrm{~h}$ for the slowest loading rate with a $70 \%$ preload. 
periods is a result of a thermally activated process involving interaction of the environment and the sample. Since AlN is thermodynamically unstable in water vapor and decomposes by the reaction

$$
\mathrm{AlN}+3 \mathrm{H}_{2} \mathrm{O} \Rightarrow \mathrm{Al}(\mathrm{OH})_{3}+\mathrm{NH}_{3}
$$

it was felt that testing AlN in an environment of nitrogen saturated with water vapor would show the greatest effects of atmosphere. Therefore, testing utilized nitrogen flowing at $100 \mathrm{sccm}$ and bubbled through distilled water. This gas stream was directed onto the tensile surface of the sample using gas flow channels in the coaxial ring flexure fixture. The flowing gas, coupled with the sealing action of the lower loading ring, assured that the desired atmosphere on the tensile surface was achieved and maintained. The gas mixture was allowed to flow for a minimum of 5 minutes prior to loading the sample to assure that the atmosphere was equilibrated.

In order to produce controlled flaws in the AlN samples, the tensile surface was indented with a Vicker's indenter immediately prior to testing. Preliminary work showed that an indentation load of $14.7 \mathrm{~N}$ was sufficient to produce well developed radial cracks systems without chipping; this indentation load was used for all dynamic fatigue testing.

AlN - O Dynamic Fatigue: Dynamic fatigue data for AlN - 0 are given in Fig 20 for differences in stressing rates of 4 orders of magnitude. While the scatter in the fracture stress for any given stressing rate appears large, this is a result of the logarithmic strength scale employed. As expected, with decreasing stressing rates the average fracture strength decreased. The very low slope is indicative of a low influence of atmosphere on strength, as indicated by the high N' value of 125 . For reference, typical N' values for silicate glasses, which show a moderate sensitivity to moisture, are on the order of 15 to 20 .

There is, however, significant overlap of the fracture strengths over the 4 orders of magnitude in stressing rates employed. Included in this figure are data from two tests in which water vapor was absent from the gas atmosphere, labeled dry $\mathrm{N}_{2}$. These data also fit well with the data from the water saturated $\mathrm{N}_{2}$, further supporting the conclusion that water vapor has small effect on strength in this material. 


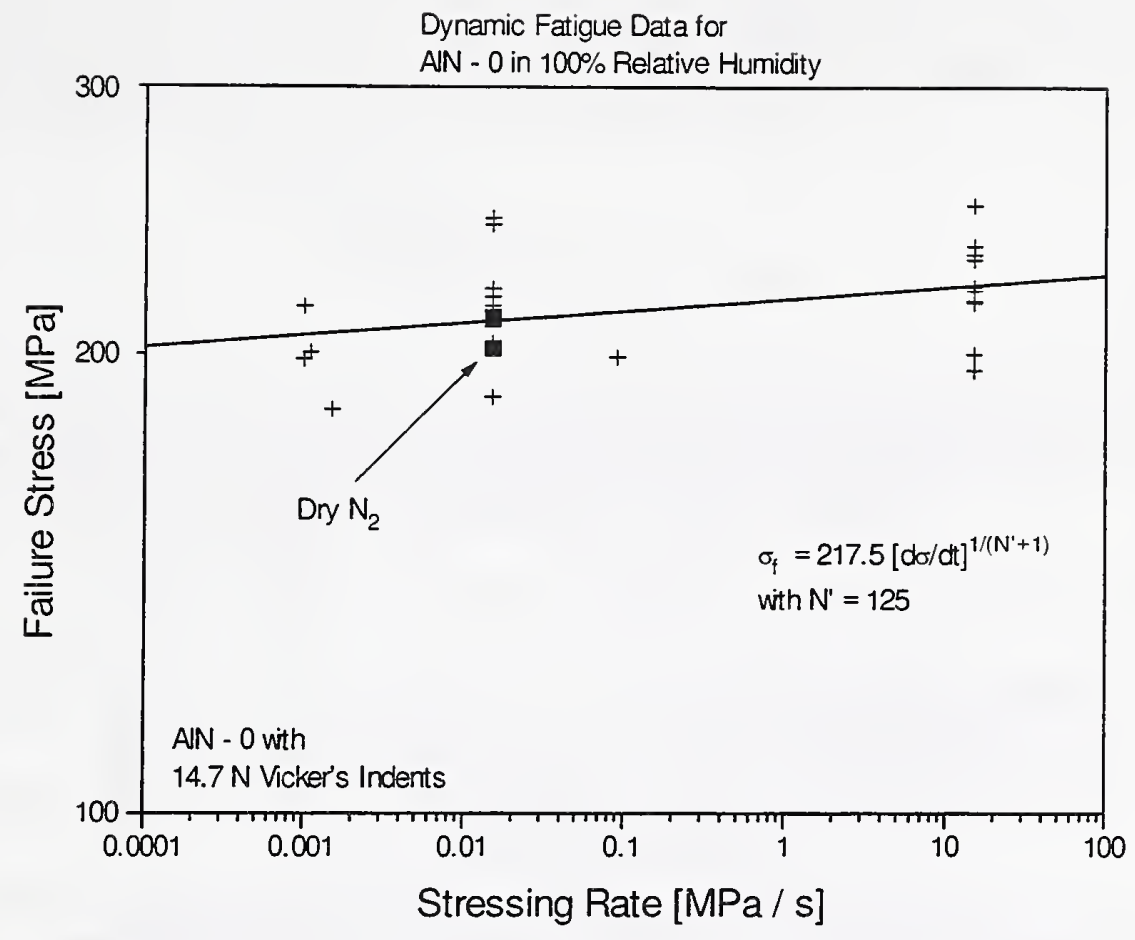

Figure 20. Dynamic fatigue data for AlN - 0 samples in nitrogen saturated with water vapor at room temperature.

AlN - 1 Dynamic Fatigue: Similar measurements performed on the AlN-1 material show the same trend of low sensitivity to stressing rate in moist atmospheres (Fig. 21), as shown by the nearly flat to slightly negative slope. A regression line through these data yields an $N^{\prime}$ value of -89 . Although negative values of $\mathrm{N}^{\prime}$ are unphysical, since they indicate that the material becomes stronger when stressed for long periods of time, such behavior has been observed elsewhere. ${ }^{25}$ A more likely explanation of the negative $N^{\prime}$ value is based on the sampling statistics. Since $N^{\prime}+1$ is the reciprocal of the slope, when the slope of the regression line is nearly zero, small scatter in the data can result in large changes in $\mathrm{N}^{\prime}$, including negative values. Statistically, the confidence interval of the $N^{\prime}$ value can be related to the confidence interval, or scatter, of the measurements taken at the two extremes in the stressing rate. ${ }^{26}$ Assuming normal statistics for the log of the failure strengths, rearranging the defining equation for $\mathrm{N}^{\prime}$ (Eq. 7) and changing the derivative to a finite difference of the fastest and slowest loading rates: 


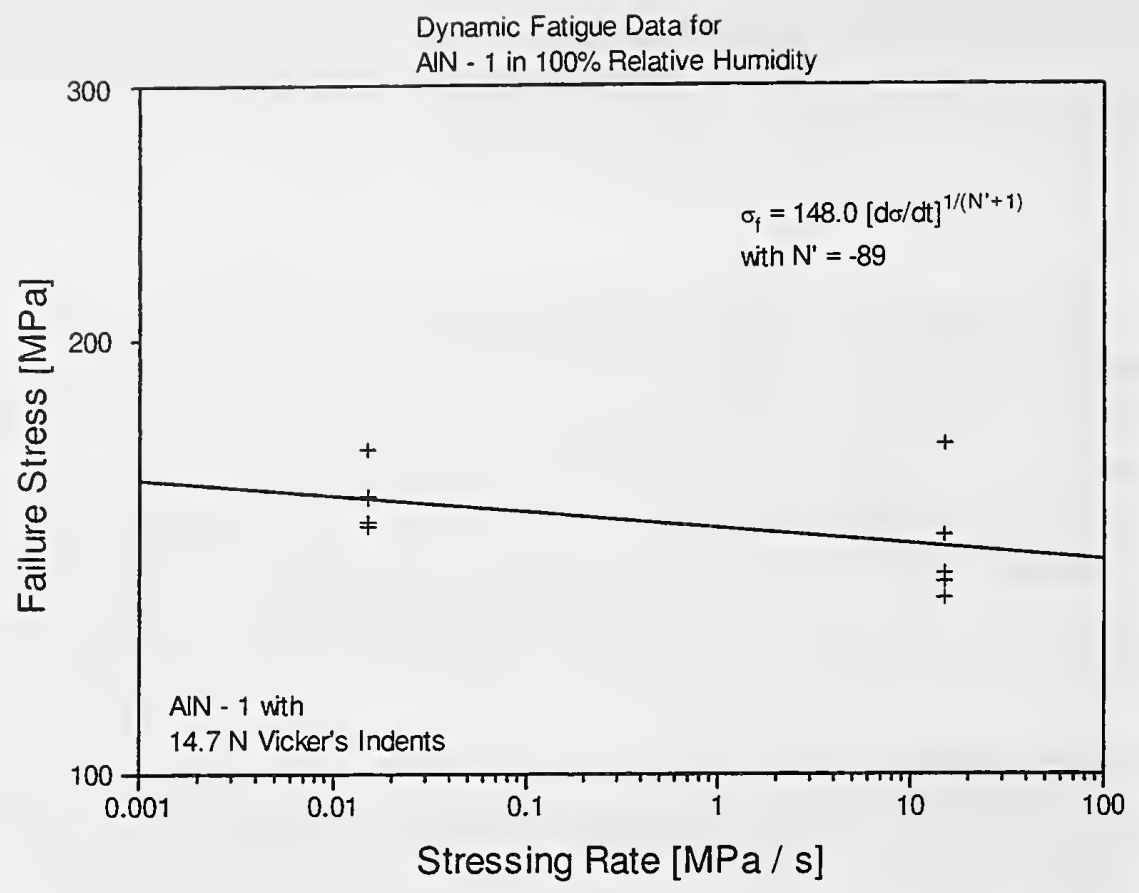

Figure 21. Dynamic fatigue of AlN - 1 in water saturated $\mathrm{N}_{2}$ atmosphere.

$$
\text { Slope }=\frac{1}{N^{\prime}+1}=\frac{\log \left(\sigma_{f_{2}}\right)-\log \left(\sigma_{f_{1}}\right)}{\log \left(\dot{\sigma}_{2}\right)-\log \left(\dot{\sigma}_{1}\right)}
$$

The denominator is the difference in the log of the applied stressing rates and the numerator is the difference in the log of the mean failure stresses corresponding to each loading rate. Assuming that the error in the measurement of loading rate is insignificant compared to the variations in fracture strength, the variation in $\mathrm{N}^{\prime}$ is dependent only on scatter in measurement of the mean failure strengths at the two loading rates. The number of samples needed at each loading rate to estimate a difference of the means within $\delta_{s}$ units is:

$$
n_{1}=n_{2}=\left(\frac{z_{\alpha / 2}}{\delta_{s}}\right)^{2}\left(S D_{1}^{2}+S D_{2}^{2}\right)
$$


where $\mathrm{z}_{\alpha / 2}=1.65$ for a $90 \%$ confidence interval and $\mathrm{SD}_{\mathrm{i}}$ is the standard deviation of the log of the strengths at each respective loading rate. For a practical range of loading rates of five orders of magnitude difference and an estimated value of $\mathrm{N}^{\prime}$ of 125 , a $20 \%$ variation in the value of $N^{\prime}$ would give:

$$
\delta s=(20 \%)(5 / 125)=0.008
$$

Substituting present values for measured standard deviations of each of the three materials gives an estimate of the number of samples needed to obtain an N' value within $20 \%$ of its actual value with a $90 \%$ confidence interval.

For AlN - 0: $\mathrm{SD}_{1}=0.03257$ and $\mathrm{SD}_{2}=0.02311$ to give $\mathrm{n}_{1}=\mathrm{n}_{2}=68$ specimens.

For AlN - 1: $\mathrm{SD}_{1}=0.04295$ and $\mathrm{SD}_{2}=0.02134$ to give $\mathrm{n}_{1}=\mathrm{n}_{2}=98$ specimens.

For AlN - 2: $\mathrm{SD}_{1}=\mathrm{SD}_{2}=0.08508$ to give $\mathrm{n}_{1}=\mathrm{n}_{2}=308$ specimens.

The relatively large standard deviations in the measured strengths of AlN - 1 and AlN - 2, coupled with the small slope (high N'value) requires that large numbers of samples must be tested in order to obtain an accurate estimate of N'. Clearly, measurement of 4 to 5 samples of AlN - 1 is inadequate to obtain an accurate

Table I. AlN Data Summary.

\begin{tabular}{|c|c|c|c|c|}
\hline Measurement & AlN - 0 & \multicolumn{2}{|c|}{$\begin{array}{c}\text { AlN - } 1 \\
\text { Translucent Opaque } \\
\end{array}$} & AlN - 2 \\
\hline $\begin{array}{l}\text { Density } \\
{\left[\mathrm{Mg} / \mathrm{m}^{3}\right]}\end{array}$ & $\begin{array}{r}3.324 \\
\pm 0.003\end{array}$ & $\begin{array}{r}3.299 \\
\pm 0.012\end{array}$ & $\begin{array}{r}3.228 \\
\pm 0.102\end{array}$ & $\begin{array}{r}3.286 \\
\pm 0.013\end{array}$ \\
\hline $\begin{array}{l}\text { Weibull } \mathrm{m} \\
\mathrm{S}_{\mathrm{o}}[\mathrm{MPa}]\end{array}$ & $\begin{array}{r}14.3 \\
403.5 \\
\end{array}$ & \multicolumn{2}{|c|}{$\begin{array}{r}6.6 \\
351.6 \\
\end{array}$} & $\begin{array}{r}2.3 \\
220.4 \\
\end{array}$ \\
\hline $\begin{array}{l}\text { ISB Toughness } \\
{[\mathrm{MPa} \cdot \sqrt{\mathrm{m}}]}\end{array}$ & $\begin{array}{r}3.6 \\
\pm 0.3 \\
\end{array}$ & $\begin{array}{r}2.5 \\
\pm 0.4\end{array}$ & $\begin{array}{r}2.0 \\
\pm 0.3\end{array}$ & $\begin{array}{r}2.4 \\
\pm 0.3\end{array}$ \\
\hline $\begin{array}{l}\text { Dynamic } \\
\text { Fatigue } N^{\prime}\end{array}$ & 125 & \multicolumn{2}{|c|}{-89} & $\begin{array}{c}\text { not } \\
\text { measured }\end{array}$ \\
\hline
\end{tabular}


estimate of the slope. Thus, it is not surprising that a relatively large positive, or negative value was obtained. Since these testing requirements were in excess of the number of samples available, no further dynamic fatigue testing was performed on AlN - 1 or AlN - 2.

\section{Phase Analysis}

The phase on the surfaces of the as-received AlN samples were determined by $\mathrm{x}$ ray diffraction (XRD). The results of these measurements are given in Fig. 22. For all AIN samples, the primary crystalline phase present is AIN. The crystalline second phases present are different in each sample. AlN - 0 contains almost exclusively yttrium aluminum garnet $\left(\mathrm{YAG}, 3 \mathrm{Y}_{2} \mathrm{O}_{3}: 5 \mathrm{Al}_{2} \mathrm{O}_{3}, \mathrm{JCPDS}^{27}\right.$ card \#3340). Three small, unidentified peaks exist at $31.7^{\circ}, 37.4^{\circ}$ and $45.5^{\circ} 2 \theta(\mathrm{Cu}-\mathrm{K} \alpha$ radiation). These unidentified peaks could not be indexed to either the monoclinic (YAM, $2 \mathrm{Y}_{2} \mathrm{O}_{3}: 1 \mathrm{Al}_{2} \mathrm{O}_{3}$, JCPDS 34-368) or perovskite (YAP, $1 \mathrm{Y}_{2} \mathrm{O}_{3}: 1 \mathrm{Al}_{2} \mathrm{O}_{3}$, JCPDS 38-222) yttrium aluminate phases.

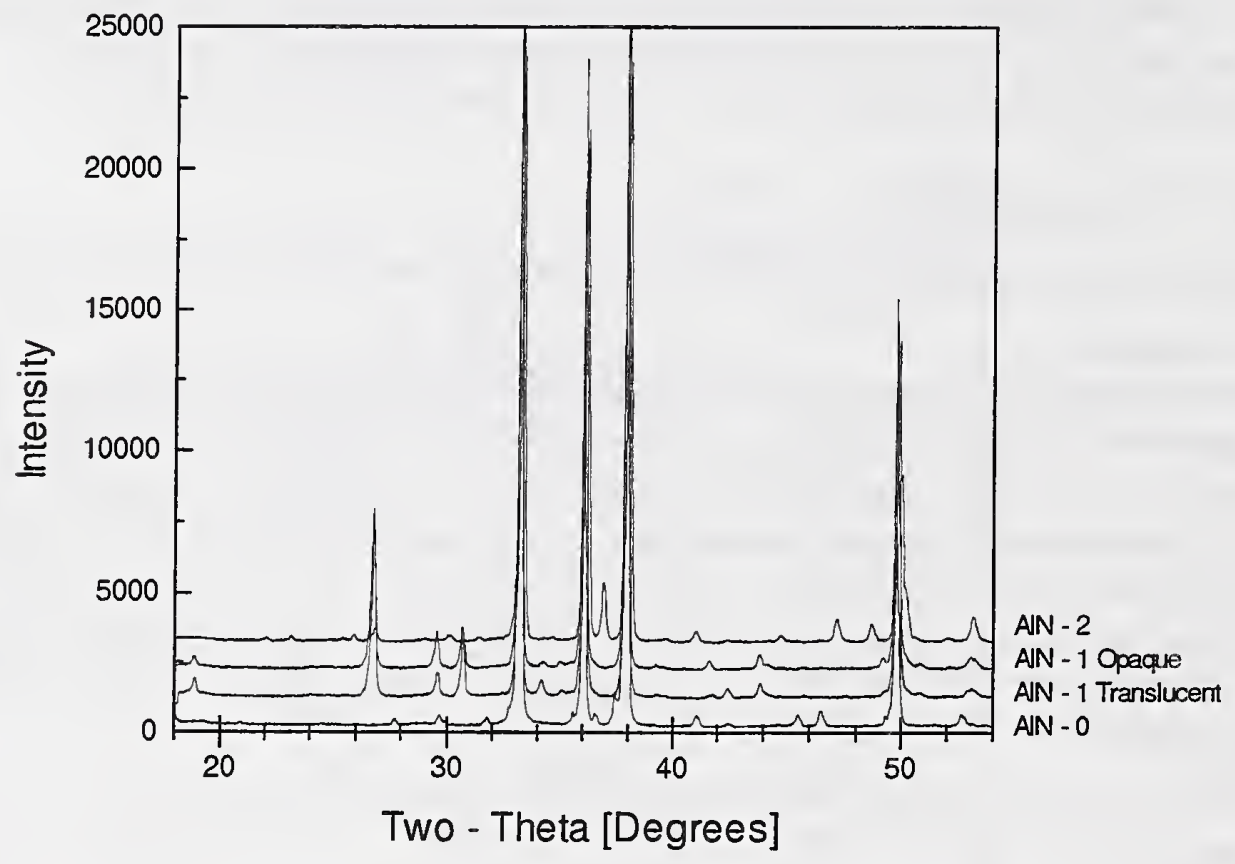

Figure 22. XRD data for the AlN materials. The primary phase in each is AlN but the secondary phases are different. 
Only minor differences were found between the translucent and opaque AlN - 1 samples. The translucent and opaque AlN - 1 samples seemed to have only YAM present on the surface. The opaque AlN - 1 samples also had an unidentified peak at $41.6^{\circ} 2 \theta$. The second phases could not be indexed to the ternary $\mathrm{CaYAlO}_{4}$ phase or binary $\mathrm{CaO}-\mathrm{Y}_{2} \mathrm{O}_{3}$ phases.

Phase analysis of AlN - 2 did not show any of these three yttrium aluminate phases but other, unidentified phase(s).

It should be noted that the phases identified by XRD are the phases present on the as-received surface and may not be representative of those present in the interior.

\section{Microstructural Observations}

Microstructural observations of unetched polished sections using scanning electron microscopy ${ }^{* *}(\mathrm{SEM})$ also showed significant differences.

AlN - Q: The AlN - 0 samples showed a very well dispersed, equiaxed, isolated second phase at the AlN grain boundaries (Fig. 23A). At higher magnifications it is apparent that the YAG phase has a large contact angle with the AlN (Fig. 23B); there were no indications of AlN boundary wetting. This behavior was unexpected since, for a liquid phase to be advantageous in promoting densification, wetting behavior is desirable. One possible explanation for this inconsistency is that the contact angle increases as the material cools from the sintering temperature. The final geometric configuration is frozen in when the second phase as well as the AlN matrix both have insufficient atomic mobility to change the space filling geometry.

AlN - 1: Initial observations of polished AlN - 1 sections showed a system with an apparent inhomogeneous dispersion of second phase; some relatively large areas seemed to be devoid of the yttrium aluminate phase. (Fig. 24A.) Closer examination, however, showed the areas devoid of the yttrium aluminate phase resulted from pull-outs of the second phase during polishing. Since all of the samples were simultaneously polished using the same conditions, these pull-outs might have resulted from high internal stresses in this sample, as compared to those in AlN - 0. As with the AlN - 0 sample, high magnification shows the second phase appears to be non-wetting (Fig. 24B).

"The authors wish to acknowledge James Kelly for his SEM work. 

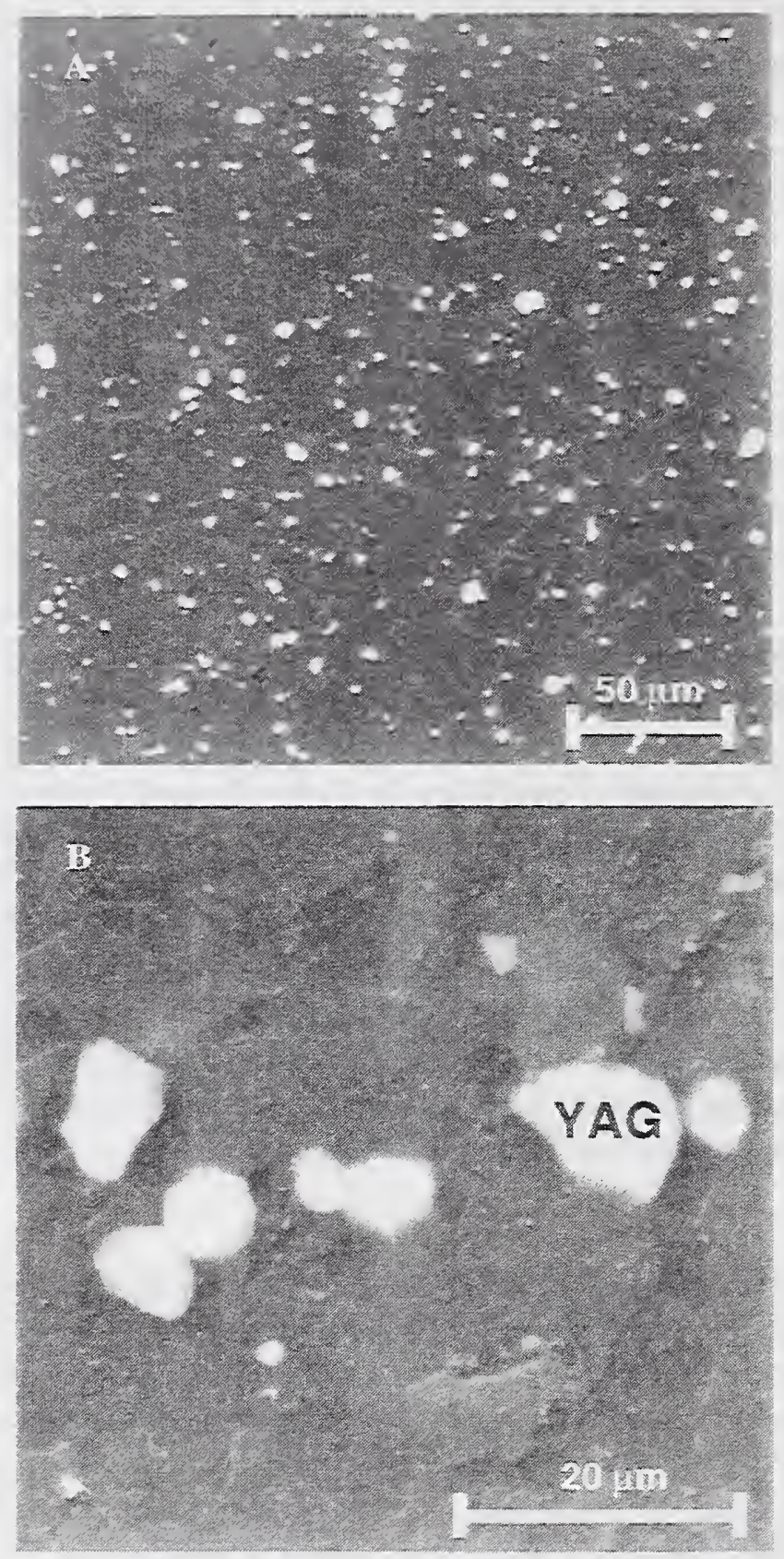

Figure 23 Polished section of AlN - 0 sample showing A)homogeneous distribution of $Y A G$ and $B$ ) large contact angle of solid $Y A G$ with the AIN matrix. 

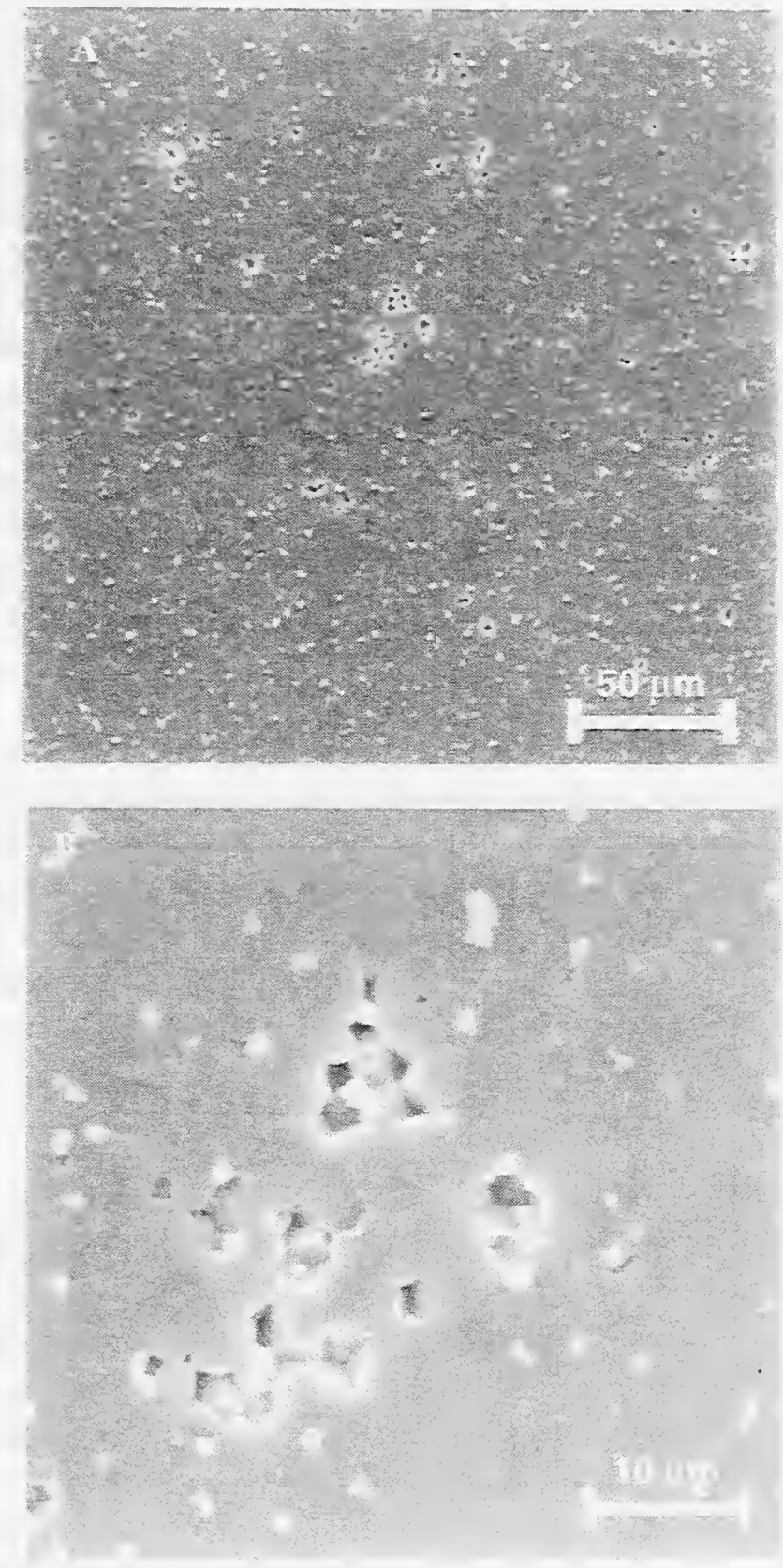

Figure 24 Polished section of translucent AlN - 1 sample. A) The apparent inhomogeneous distribution of $\mathrm{Y}^{2} \mathrm{O} \mathrm{O} 3$ - containing second phase is shown $\mathrm{B}$ ) 10 he primarily the result of pull-outs. 
Opaque AlN - 1 samples appeared more extreme in their behavior. At low magnification the distribution of second phase appeared to be even more inhomogeneous than that of the translucent AlN - 1 samples. (Fig. 25) Here, also, the areas devoid yttrium aluminate were a result of polishing pull-outs (Fig. 26A). Also, the second phase particles which were previously non-wetting, now had a much smaller contact angle and frequently had internal cracks (Fig. 26B). Preliminary energy dispersive spectroscopy (EDS) measurements showed these particles to have increased yttrium to aluminum ratios. One possible explanation is that the initial effective oxygen content of the $\mathrm{AlN}-1$ powder was lower than that of the $\mathrm{AlN}$ - 0 powder thus, for the same $\mathrm{Y}_{2} \mathrm{O}_{3}$ additions, the yttrium to aluminum ratio was greater in the AlN - 1 samples. The cracking observed in the individual clusters of grains in these samples could have linked along wetted boundaries and resulted in larger flaws which could have lowered strength. It must be reiterated that this is very speculative.

AlN - 2: The behavior of AlN - 2 was more complex. A large degree of inhomogeneity was obvious in these samples. (Fig. 27) Here, however, the apparent inhomogeneity was real and not a result of pull-outs (Fig. 28A). Clusters of second phase rich regions covering $50 \mu \mathrm{m}$ were apparent. In general, the second phase appeared to have a relatively low contact angle. Even on a very fine scale, there were changes in contact angle (Fig 28B), suggesting chemical inhomogeneities on this scale. Cracks in the second phase were not observed.

\section{DISCUSSION AND CONCLUSIONS}

A wealth of data has been gathered on a series of samples which are physically quite different. The consistency in properties of AlN - 0 demonstrates the skill that has been developed during large scale production of this material, while the variations in AlN - 1 and $\mathrm{AlN}$ - 2 show the learning process associated with the small scale processing of prototype materials. Beyond these changes in production conditions, the AlN powder sources, dopant systems and firing conditions were also varied. The variations in the basic material brought out by these changes is most clearly shown in composition of the second phases present in the final materials. Although AlN - 0 and AlN - 1 nominally had the same dopant content and were sintered under similar conditions, the second phases produced were different. (Fig. 22) The differences were even more pronounced for AlN - 2 where the basic composition of the dopant package, as well as the sintering temperature and time, were vastly different. The differences in second phase composition and structure could have profound influence on the mechanical properties through any 

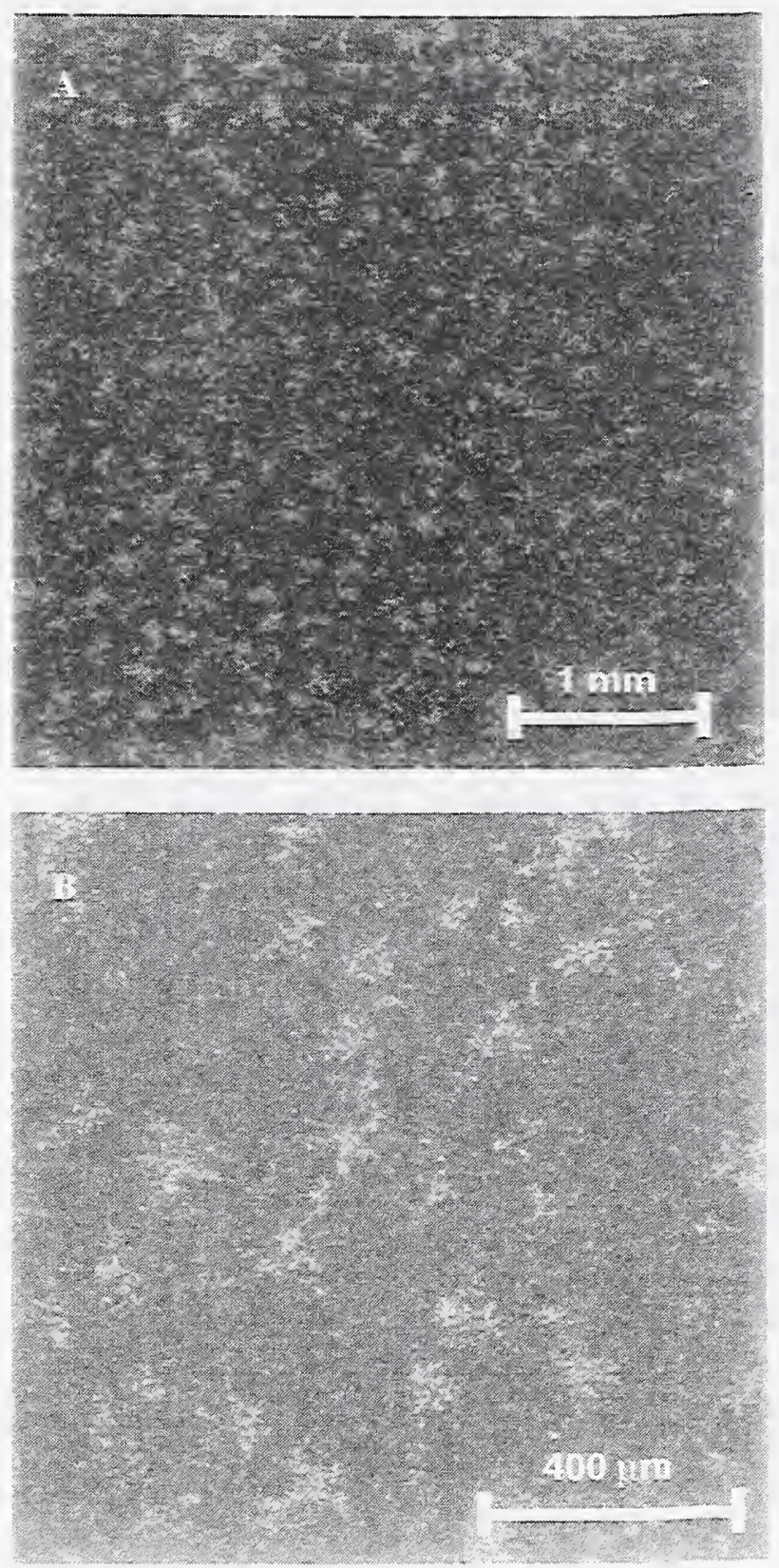

Figure 25 Polished section of opaque $A l N-1$. The distribution of $\mathrm{Y} \geq \mathrm{O}:-$ containing second phase appears to be quite inhomogeneous at low magnification. 

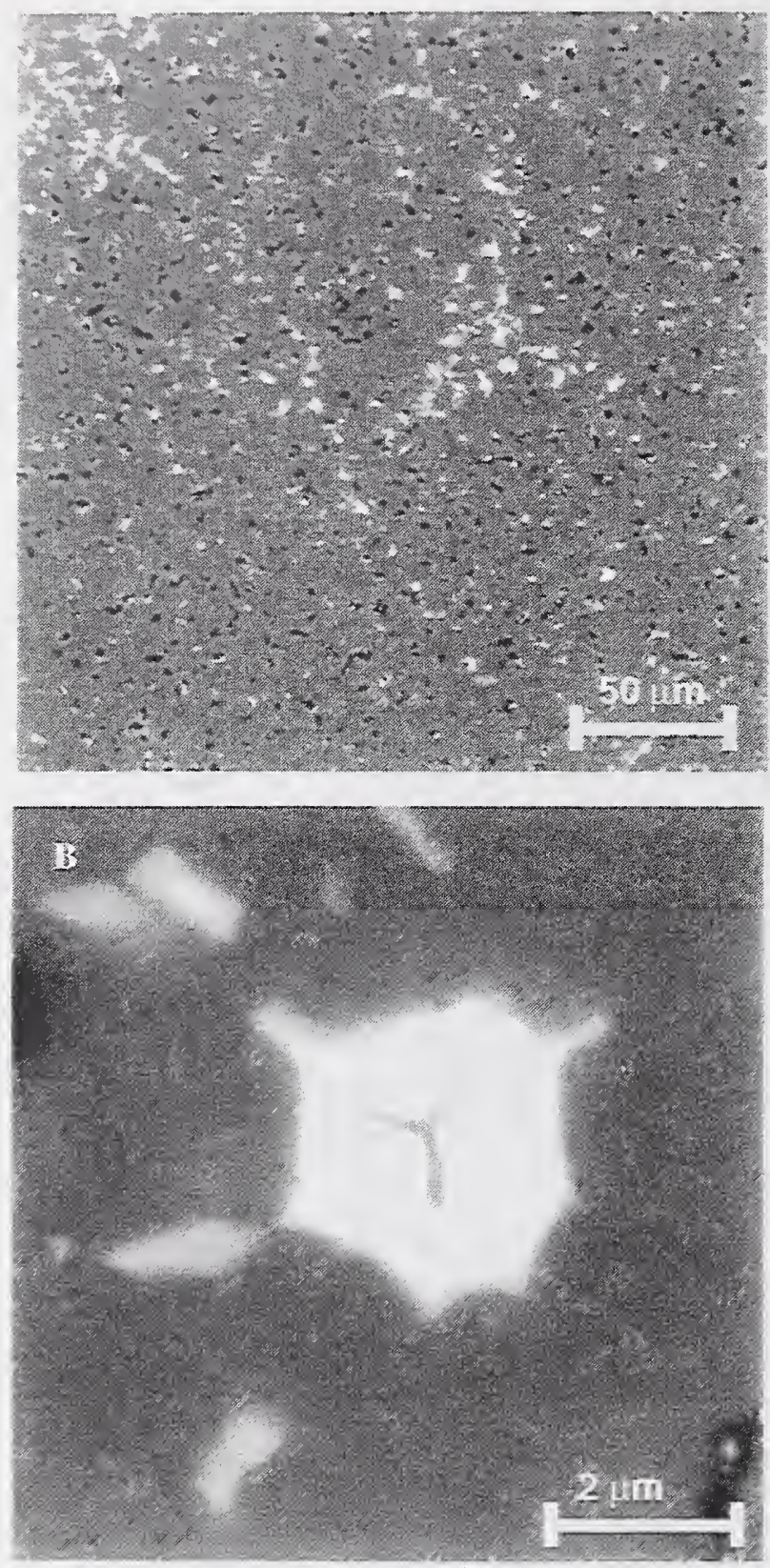

Figure 26 Polished section of opaque $\mathrm{AIN}-1$. A) Areas devoid of $\mathrm{Y}_{2} \mathrm{O} 3-$ containing second phase were the result of pull-outs. B) The contact angle of the second phase decreased significantly from that in AIN - 0 and cracks were found in many of the second phase particles. 

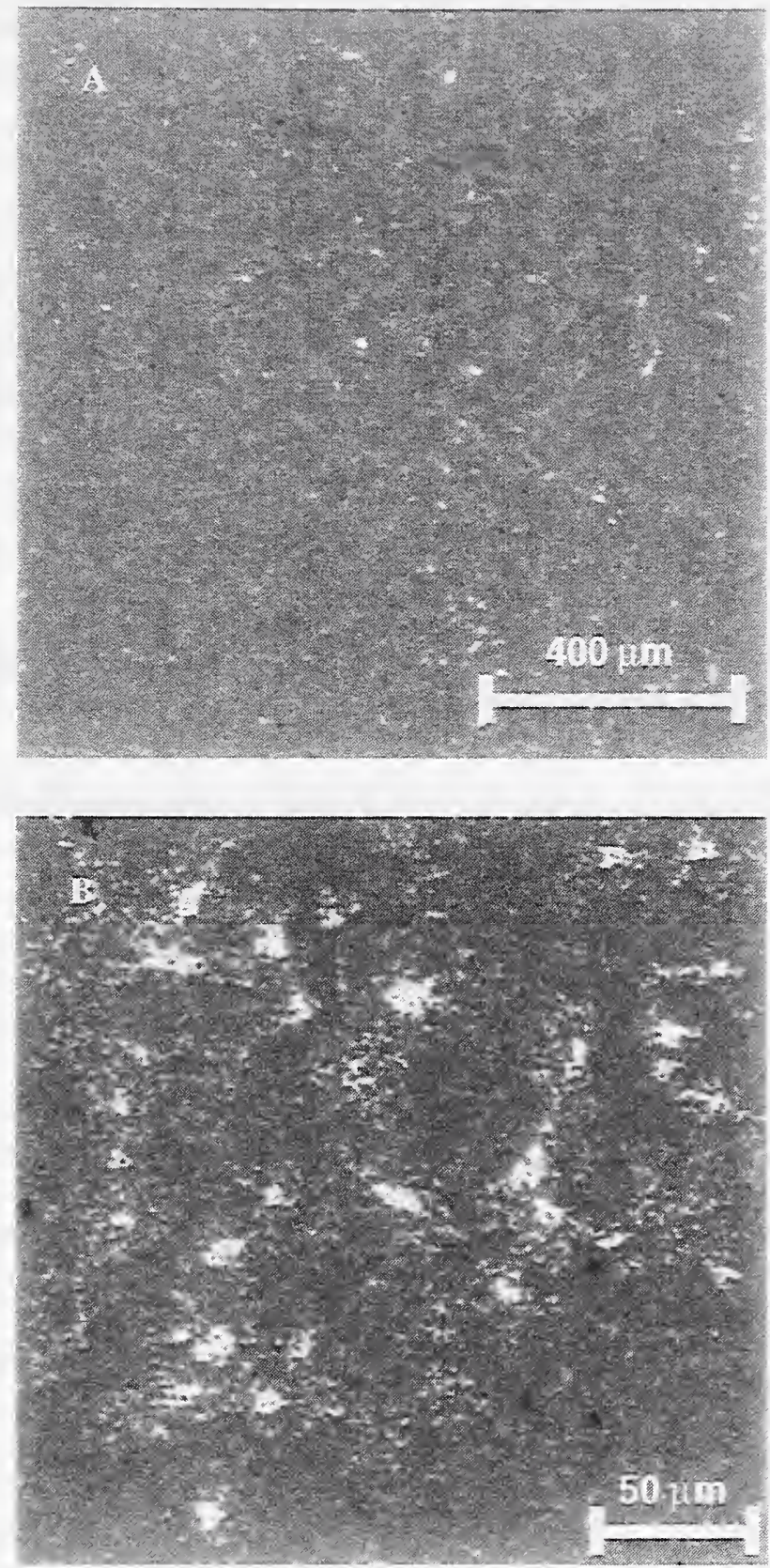

Figure 27 Polished section of AlN - 2. A large degree of inhomogeneity was apparent in AIN - 2 samples both at A) low magnification and B) higher magnification. 

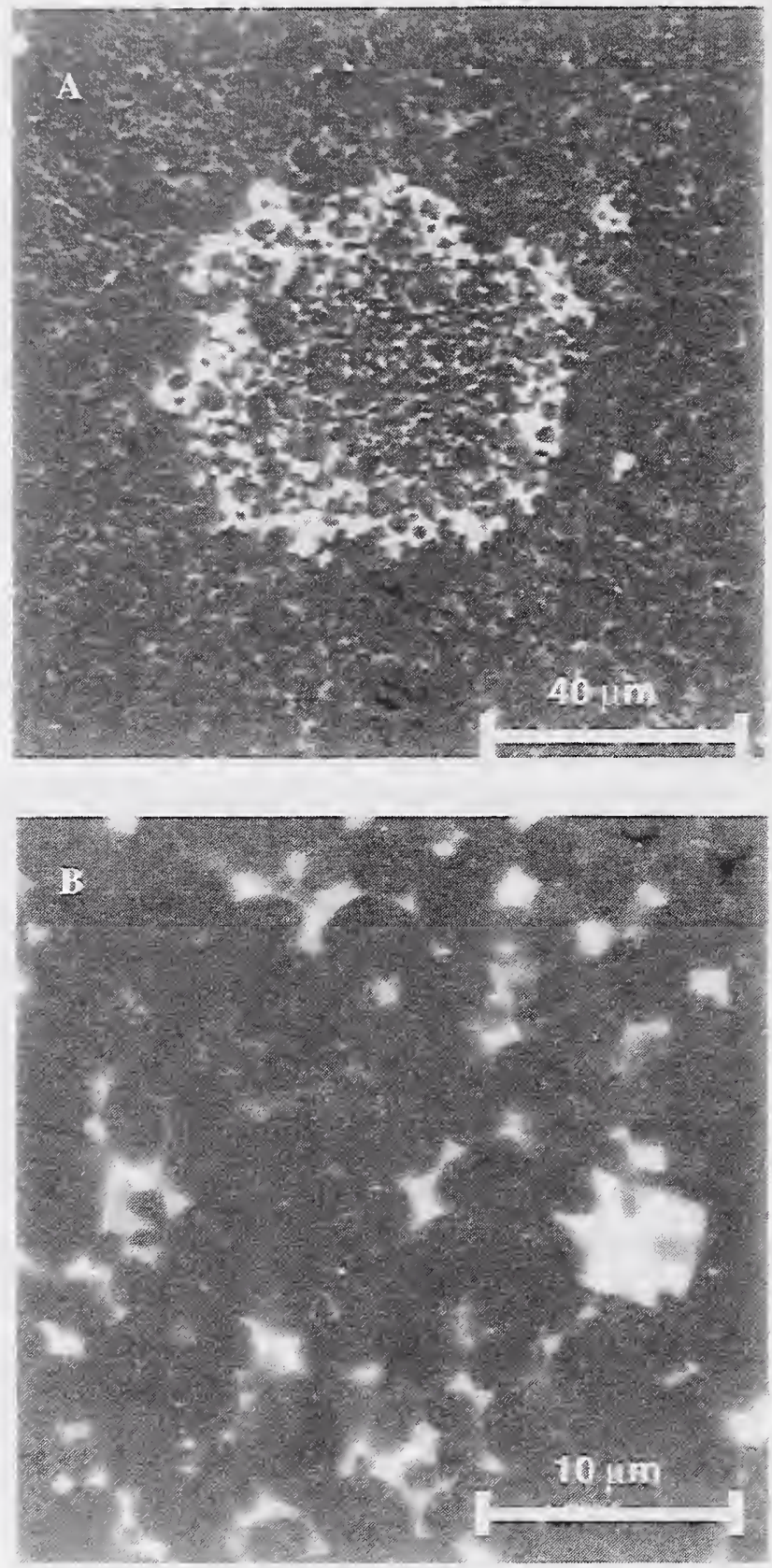

Figure 28 Polished section of AlN - 2. A) Inhomogeneity present in AIN - 2 samples was not the result of pull-outs. B) Chemical imhomogencitics may lead to changes in contact angle with the matrix even on a fine scale. 
number of possible variables: wetting behavior and distribution of second phase in the AIN matrix; differences in coefficient of thermal expansion mismatch between the second phase and the matrix; elastic modulus changes; and interfacial bond strength between the AIN and the second phase. As a result, it is almost surprising that the three materials are so similar in their properties.

This investigation into the mechanical properties of AlN is preliminary; differences in materials and properties have been noted and hypotheses concerning the causes of these differences have been proposed. Based on this substantial beginning, further effort on the basic factors influencing the mechanical properties in these relatively complex systems has been planned.

\section{References}

1. "Standard Test Method for Flexural Strength of Advanced Ceramics at Ambient Temperature," American Society for Testing and Materials, ASTM C 1161 - 90 (1990).

2. "Advanced Technical Ceramics - Monolithic Ceramics - Mechanical Properties at Room Temperature, Part 1. Determination of Flexural Strength," European Standard EN 843-1, (1995).

3. "Testing Method for Flexural Strength (Modulus of Rupture) of High Performance Ceramics," Japanese Industrial Standard, JIS R 1601 (1981).

4. J. B. Wachtman, Jr., W. Capps, and J. Mandel, "Biaxial Flexure Tests of Ceramic Substrates," J. Mat., 7 [2], 188-194 (1972).

5. ASTM, "Standard Test Method for Biaxial Flexure Strength (Modulus of Rupture) of Ceramic Substrates," American Society for testing and Materials, ASTM F394 - 78 (1978).

6. D. B. Marshall, "An Improved Biaxial Flexure Test for Ceramics,” Am. Ceram. Soc. Bull., 59 [5], 551-553 (1980).

7. G. De With and H. H. M. Wagemans, "Ball-on-Ring Test Revisited," J. Am. Ceram. Soc., 72 [8], 1538-1541 (1989).

8. D. K. Shetty, A. R. Rosenfield, W. H. Duckworth and P.R. Held, "A Biaxial-Flexure Test for Evaluating Ceramic Strengths," J. Am. Ceram. Soc., 66 [1], 36 - 42 (1983).

9. “Determination of Bending Strength," Deutsches Institut für Normung, 52292 (1984). 
10. K. M. Entwistle, "The Fracture of Concentrically Loaded Square Ceramic Plates," J. Mat. Sci., 26 [2], 1078-1086 (1991).

11. W. F. Adler and D. J. Mihora, "Biaxial Flexure Testing: Analysis and Experimental Results," p. 227 in Fracture Mechanics of Ceramics Vol. 10, R. C. Bradt et al. (eds) Plenum Press (1992).

12. Plastics 1980: A Desk-top Data Bank, The International Plastics Selector, Inc. (1980).

13. D. K. Shetty, A. R. Rosenfield, P. McGuire, G. K. Bansal, and W. H. Duckworth, "Biaxial Flexure Tests for Ceramics," Am. Ceram. Bull., 59 [12], 1193-1197 (1980).

14. H. Fessler and D. C. Fricker, "A Theoretical Analysis of the Ring-on-Ring Loading Disk Test," J. Am. Ceram. Soc., 67 [9], 582-588 (1984).

15. D. Gerlick, S. L. Dole and G. A. Slack, "Elastic Properties of Aluminum Nitride," J. Phys. Chem. Solids, 47 [5], 437-441 (86).

16. J. E. Ritter, Jr., K. Jacus, A. Batakis and N. Bandyopadhyay, “Appraisal of Biaxial Strength Testing," J. Non-Cryst. Solids, 38-39, 419-424 (1980).

17. B. R. Lawn, Fracture of Brittle Solids, Cambridge University Press (1995).

18. "Standard Practice for Reporting Uniaxial Strength Data and Estimating Weibull Distribution Parameters for Advanced Ceramics," American Society of Testing and Materials, ASTM C 1239-94a (1994).

19. G. R. Anstis, P. Chantikul, B. R. Lawn, and D..B. Marshall, "A Critical Evaluation of Indentation Techniques for Measuring Fracture Toughness: I, Direct Crack Measurements," J. Am. Ceram. Soc., 64 [9], 533-538 (1981).

20. P. Chantikul, G. R. Anstis, B. R. Lawn, and D. B. Marshall, "A Critical Evaluation of Indentation Techniques for Measuring Fracture Toughness: II, Strength Method," J. Am. Ceram. Soc., 64 [9], 539-543 (1981).

21. C. F. Cline and J. S. Kahn, "Microhardness of Single Crystals of BeO and Other Wurtzite Compounds," J. Elchem. Soc. [110], 773 (1963).

22. D. B. Marshall and B. R. Lawn, "Flaw Characteristics in Dynamic Fatigue: The Influence of Residual Contact Stresses," J. Am. Ceram. Soc., 63 [9 - 10], 532-536 (1980). 
23. E. R. Fuller, Jr., B. R. Lawn, and R. F. Cook, "Theory of Fatigue for Brittle Flaws Originating from Residual Stress Concentrations," J. Am. Ceram. Soc., Vol. 66, No. [5], 314-321 (1983).

24. S. R. Choi, "Effect of Preloading on Fatigue Strength in Dynamic Fatigue Testing of Ceramic Materials at Elevated Temperatures," Ceramic Engineering and Science Proceedings 16 [4], 87-94 (1995).

25. M. E. O'Day, and G. L. Leatherman, "Static Fatigue of Aluminum Nitride Packaging Materials," Int. Soc. Hybrid Microelectronics, 16 [1], $41-47$ (1993).

26. W. Mendenhall, and T. Sincich, p. 313 in Statistics for Engineering and the Sciences 3'rd edition, Dellen Publishing Co (1992).

27. International Centre for Diffraction Data, Newtown Square Pennsylvania, USA. 

忐芯

N

승

$\exists$. ฮั่

…

สำ

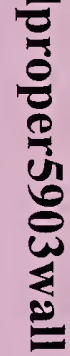

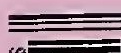

